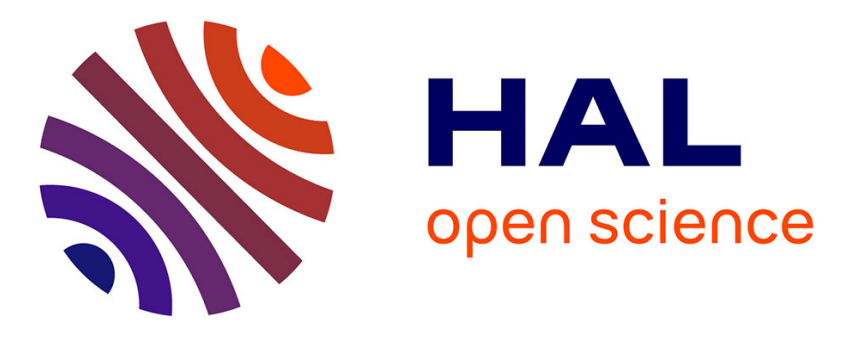

\title{
Multifrequency radar imagery and characterization of hazardous and noxious substances at sea.
}

Sébastien Angelliaume, Brent Minchew, Sophie Chataing, Philippe Martineau, Véronique Miegebielle

\section{To cite this version:}

Sébastien Angelliaume, Brent Minchew, Sophie Chataing, Philippe Martineau, Véronique Miegebielle. Multifrequency radar imagery and characterization of hazardous and noxious substances at sea.. IEEE Transactions on Geoscience and Remote Sensing, 2017, 55 (5), pp.3051-3066. 10.1109/TGRS.2017.2661325 . hal-01559106

\section{HAL Id: hal-01559106 https://hal.science/hal-01559106}

Submitted on 4 Oct 2021

HAL is a multi-disciplinary open access archive for the deposit and dissemination of scientific research documents, whether they are published or not. The documents may come from teaching and research institutions in France or abroad, or from public or private research centers.
L'archive ouverte pluridisciplinaire $\mathbf{H A L}$, est destinée au dépôt et à la diffusion de documents scientifiques de niveau recherche, publiés ou non, émanant des établissements d'enseignement et de recherche français ou étrangers, des laboratoires publics ou privés. 


\title{
Multifrequency Radar Imagery and Characterization of Hazardous and Noxious Substances at Sea
}

\author{
Sébastien Angelliaume, Brent Minchew, Sophie Chataing, Philippe Martineau, and Véronique Miegebielle
}

\begin{abstract}
The increase in maritime traffic, particularly the transport of hazardous and noxious substances (HNSs), requires advanced methods of identification and characterization in environmental chemical spills. Knowledge about HNS monitoring using radar remote sensing is not as extensive as for oil spills; however, any progress on this issue would likely advance the monitoring of both chemical and oil-related incidents. To address the need for HNS monitoring, an experiment was conducted in May 2015 over the Mediterranean Sea during which controlled releases of HNS were imaged by a multifrequency radar system. The aim of this experiment was to establish a procedure for collecting evidence of illegal maritime pollution by noxious liquid substances using airborne radar sensors. In this paper, we demonstrate the ability of radar imagery to detect and characterize chemicals at sea. A normalized polarization difference parameter is introduced to quantify both the impacts of released product on the ocean surface and the relative concentration of the substance within the spill. We show that radar imagery can provide knowledge of the involved HNS. In particular, one can distinguish a product that forms a film on the top of the sea surface from another that mixes with seawater, the information that is critical for efficient cleanup operations.
\end{abstract}

Index Terms-Chemical, hazardous and noxious substance (HNS), ocean, oil, oil and water mixing index, multifrequency, normalized polarization difference (NPD), polarimetry, pollution, sea surface, slick, spill, synthetic aperture radar (SAR).

\section{INTRODUCTION}

A IRBORNE and spaceborne remote sensing techniques are of great interest for monitoring maritime pollution [1], [2]. Slicks are often detected using real aperture radar or synthetic aperture radar (SAR) because radar can be used any time and in almost any weather conditions [3]-[7]. For remote sensing applications, the ocean surface is usually modeled as the superposition of waves of different scales. At high frequency (microwave domain) and at moderate

S. Angelliaume and P. Martineau are with the Electromagnetism and Radar Department, ONERA, 13661 Salon-de-Provence, France (e-mail: sebastien.angelliaume@onera.fr; philippe.martineau@onera.fr).

B. Minchew is with the British Antarctic Survey, Cambridge, UK (e-mail: bremin15@bas.ac.uk)

S. Chataing is with the Research and Development Department, CEDRE, 29200 Brest, France (e-mail: sophie.chataing.pariaud@cedre.fr).

$\mathrm{V}$. Miegebielle is with the Research and Development Department, TOTAL, 64018 Pau, France (e-mail: veronique.miegebielle@ total.com). incidence angles $\left(30^{\circ}-60^{\circ}\right)$, slick-free sea surface scattering calls for Bragg or tilted-Bragg scattering: the electromagnetic (EM) wave resonates with ocean waves with wavelengths comparable to the transmitted radar wavelength [8]. The slick layer on top of the sea surface damps these waves [9], [10], which are the main contributors to backscattered EM signal. Reduced backscatter causes slick-covered areas to appear as dark patches in the radar image.

Traditionally, SAR slick observation is based on singlepolarization amplitude images, often vertically polarized transmit and receive (VV) radar waves. While algorithms have been developed to facilitate automatic slick detection, manual inspection is often needed [11]. Studies published in the literature have suggested the use of polarimetric SAR (POLSAR) parameters to improve the detection capability of slicks [12] and to attempt to characterize the observed pollution [13]-[17]. Nevertheless, some issues remain unresolved, such as the quantification of the spilled product or the distinction between polluted areas and look-alikes, which can arise in areas with relatively low winds, biogenic substances, or other natural sources [2].

Several parameters influence the capability of a radar sensor to detect maritime pollution. The sensor itself must be well adapted (high frequency is preferable to lower frequency [9]). Acquisitions must be made under low-to-moderate wind conditions (e.g., 2-12 m/s at C-band [5]) to ensure enough contrast between polluted and clean areas (lower limit) and to avoid too fast mixing of the product into the water column (upper limit). Under high wind speed conditions, wind-generated waves may receive enough energy to counterbalance the damping effect [18] and breaking-wave events can disperse slicks [19].

The nature of the involved substance is likewise a key issue. Marine slicks can be composed of mineral oils, including petroleum-based material, natural hydrocarbon seeps, or films from biological processes (called look-alike). However, they can also come from any other liquid substance produced by human activity, such as hazardous and noxious substances (HNSs). An HNS is defined by the International Maritime Organization (IMO) as any substance other than oil, which if introduced into the marine environment is likely to create hazards to human health, to harm living resources and marine life to damage amenities, or to interfere with other legitimate uses of the sea [20]. The effectiveness of radar remote sensing for HNS monitoring depend on the imaged product, the latter impacting the sea surface differently depending on its physical and chemical properties. In order to quickly evaluate the behavior of chemical substances 
when released at sea, the Standard European Behavior Classification (SEBC) was created in the framework of the Bonn Agreement in 1994. Based on physical and chemical properties, i.e., specific gravity, water solubility, and vapor pressure, this classification enables a first estimation of shortterm chemical substances behaviors: floating $(F)$, sinking (S), evaporating (E), and dissolving (D), with the combinations represented as floater and dissolver (FD), ED, FED, and so on. Over the frequency range of 1 to $10 \mathrm{GHz}$ (approximately L- to X-band), the penetration depth (i.e., skin depth) of seawater is between $0.1 \mathrm{~cm}$ and $1.0 \mathrm{~cm}$ [21]. Due to the shallow penetration of EM signal into seawater, radar remote sensing should be effective for monitoring only floating product, classified as $\mathrm{F}$ or a combination of $\mathrm{F}$ with another behavior such as floater and evaporator (FE). In the case of floating substance, the speed of evaporation or dissolution and the amount of released product are important because they strongly influence how the sea surface will be affected.

For decades, initiatives implemented by both the oil/shipping industry and governments have been largely focused on the fight against oil spills, which had the effect of drastically reducing the quantities discharged in oceans. For a period of 40 years (between 1970 and 2010), the average number of oil spills observed per year has fallen by more than $85 \%$ [22], [23], despite a steady increase in oil transported by sea. Similarly, the increase in marine transportation of HNS increases the risk that a marine HNS-related incident occurs. In response, the IMO has adopted a protocol aimed at providing a global framework for international cooperation in combating major incidents or threats of marine pollution from ships carrying HNS, such as chemicals. The Protocol on Preparedness, Response and Co-operation to Pollution Incidents by Hazardous and Noxious Substances (OPRCHNS Protocol) was adopted in 2000 [20], following the principles of the International Convention on Oil Pollution Preparedness, Response and Co-operation (OPRC) adopted 10 years earlier [20]. Its objectives are to advance the adoption of adequate response measures in the event that an oil pollution incident does occur and to provide for mutual assistance and cooperation between states.

In addition to this international awareness, previous accidents that have resulted in marine pollution by chemicals have highlighted the need for the use of remote sensing assets to detect various HNS at sea. A complete database of spill incidents and threats in waters around the world can be found in [24] and [25]. Use or adaptation of sensors that have been successfully employed for oil spill monitoring needs to be investigated and any progress in this issue would likely advance both the monitoring of oil and chemical pollution [26].

Despite the utility of airborne and spaceborne radar systems for detecting chemicals at sea, less effort have been devoted to HNS monitoring with radar remote sensing than to oil slicks monitoring [22]. To address this knowledge gap, an experimental campaign of measurements (called POLLUPROOF) was conducted in May 2015 in the Mediterranean Sea (off the French coast). Controlled releases of six chemical and nonhydrocarbon oil products were carried out in collaboration with the French Navy and Customs. SETHI, the ONERA (French aerospace laboratory) airborne SAR system [27], acquired POLSAR data over the released products simultaneously at X- $(9.75 \mathrm{GHz})$ and L-band $(1.325 \mathrm{GHz})$. While beyond the scope of this paper, we note that optical imagery data (LWIR, SWIR, and UV) were also acquired during this campaign.

Our goals in this paper are to better understand the capability of high-resolution multifrequency SAR imagery to detect HNS at sea and the potential of radar remote sensing to relatively quantify the concentration of released product and to distinguish between different substances. This paper is organized as follows. Section II describes the experimental measurement campaign at sea, Section III presents the methodology for detecting and characterizing liquid substances discharged at sea, and Section IV presents some original results and demonstrates the relevance of radar imagery for monitoring HNS-related pollution over maritime surface.

\section{ExPerimentation AT SeA}

\section{A. Airborne Radar Imagery}

SETHI is an airborne remote sensing imaging system developed by ONERA [27]. It integrates a new generation of radar and optronic payloads and can operate over a wide range of frequency bands from UHF and VHF to X-band, including L-band, with long-range and very high-resolution polarimetric and interferometric capabilities. SETHI is a pod-based system operating onboard a Falcon 20 Dassault aircraft, which is owned by AvDEF.

For the POLLUPROOF campaign, quad-pol SAR data were acquired at $\mathrm{X}$ - and L-band, with a range (across-track) resolution of $0.5 \mathrm{~m}$ (bandwidth from 9.6 to $9.9 \mathrm{GHz}$ ) and $1.0 \mathrm{~m}$ (bandwidth from 1.25 to $1.4 \mathrm{GHz}$ ), respectively. Images are processed with an azimuth (along-track) resolution equal to the range resolution at both $\mathrm{X}$ - and L-band, which implies an integration time equal to $1.1 \mathrm{~s}$ at X-band and $4.1 \mathrm{~s}$ at L-band. Imaged area is $9.5 \mathrm{~km}$ in azimuth and $1.5 \mathrm{~km}$ in range, with incidence angles from $34^{\circ}$ to $52^{\circ}$. The instrument noise floor has been estimated using the method proposed in [28] and the results are shown in the Appendix. The estimated Noise Equivalent Sigma ${ }^{0}$ (NESZ) is very low, ranging from around -37 to $-50 \mathrm{~dB}$ at X-band and from around -51 to $-53 \mathrm{~dB}$ at L-band, allowing a sufficient signal-to-noise ratio (SNR) over polluted areas for efficient analysis.

\section{B. Chemicals Products}

Six chemical substances have been chosen to evaluate the capability of remote sensing sensors: rapeseed oil, fatty acid methyl ester (FAME), toluene, heptane, xylene, and methanol. These chemicals are among the most transported substances by maritime freight in Europe. Methanol and liquid chemicals represent $46 \%$ of the 165 million tons annually transported by chemical carriers while vegetable oil accounts for $29 \%$ [22]. Some of these chemicals are classified as the most noxious substances in the IBC Code [20], which provides an international standard for the safe carriage by sea of HNS in bulk. Those chemicals have already been involved in accidents at sea, e.g., Poona sank in 1971 with $600 \mathrm{~T}$ of rapeseed 
oil, Grape One sank in 1993 with 3000 T of xylene, and Cape Horn carrying a cargo of $14000 \mathrm{~T}$ of methanol was seriously damaged by an explosion in the port of Leghorn in 2003 [24], [25].

Rapeseed oil and FAME are in the vegetal oil family, while toluene, heptane, and xylene are petrochemical products and methanol is a member of the family of alcohols and derivates. Their main properties are described below and their values come from the supplier of each HNS, which agree with values found in [29] and [30].

1) Rapeseed Oil: Rapeseed or colza oil is vegetal oil obtained from crushed colza seeds. At ambient pressure and temperature, rapeseed oil is a viscous liquid with a specific gravity of 0.910 . Rapeseed oil is insoluble in water and does not evaporate (vapor pressure below $0.01 \mathrm{kPa}$ at $25^{\circ} \mathrm{C}$ ); these characteristics classify rapeseed oil as a floater $\mathrm{F}$ in the SEBC.

2) FAME: FAMEs are biofuel directly added in conventional fuels such as diesel. At ambient pressure and temperature, they are a liquid with a specific gravity of 0.888 . This product is virtually insoluble in water (solubility of $0.023 \mathrm{mg} \cdot \mathrm{L}^{-1}$ at $20{ }^{\circ} \mathrm{C}$ ) and has relatively low evaporative potential (vapor pressure of $0.42 \mathrm{kPa}$ at $25^{\circ} \mathrm{C}$ ) making it a floater $\mathrm{F}$ in the SEBC.

3) Toluene: Toluene, also named methylbenzene or phenylmethane, is an aromatic hydrocarbon that is commonly used as chemical reagent or solvent, particularly in the industrial sector. Toluene is a liquid at ambient pressure and temperature and has a specific gravity of 0.867 . Toluene is nearly insoluble in water $\left(535 \mathrm{mg} \cdot \mathrm{L}^{-1}\right.$ at $25^{\circ} \mathrm{C}$ ) and tends to evaporate relatively easily (vapor pressure of $2.91 \mathrm{kPa}$ at $20{ }^{\circ} \mathrm{C}$ ). Considering the SEBC classification, toluene is a floating and evaporating $\mathrm{FE}$ substance.

4) Heptane: Heptane is the generic term to identify one of the nine isomers of $\mathrm{C}_{7} \mathrm{H}_{16}$ and is a saturated hydrocarbon of the linear alkane family. This is a constituent of fuel and is used as extraction solvent, synthesis intermediate in chemical industry, and solvent for glues, inks, rubbers and plastics. At ambient pressure and temperature, heptane is a volatile liquid (6 to $7.7 \mathrm{kPa}$ at $\left.20{ }^{\circ} \mathrm{C}\right)$ and nearly insoluble in water $\left(<2 \mathrm{mg} \cdot \mathrm{L}^{-1}\right.$ at $20{ }^{\circ} \mathrm{C}$ ). With a specific gravity of 0.710 , heptane is lighter than water and floats. According to the SEBC classification, heptane is considered as evaporator E.

5) Xylene: Xylene, or dimethylbenzene, is a group of aromatic hydrocarbons with one methyl derivative on benzene. It is naturally present in oil, xylene is observed in (diesel) engine exhaust gases, either a residual oil chemical or formed during incomplete combustion. Xylene is also produced from oil in the petrochemical industry and is one of the 30 most produced chemicals in the USA. It is used in the printing industry, rubber, and leather industries mainly as a solvent. Xylene is an inflammable liquid with a pleasant fragrance. Chemical properties are similar from one isomer to another. Its specific gravity of 0.87 makes it float on water. Xylene is slightly soluble in water $\left(146 \mathrm{mg} \cdot \mathrm{L}^{-1}\right.$ at $\left.25^{\circ} \mathrm{C}\right)$ and is not likely to evaporate (vapor pressure of $0.89 \mathrm{kPa}$ at $20{ }^{\circ} \mathrm{C}$ ). Due to these characteristics, xylene is considered as FE (floater and evaporator) in the SEBC classification.

6) Methanol: Methyl alcohol or methanol is the simplest alcohol of chemical formula $\mathrm{CH}_{3} \mathrm{OH}$. At ambient temperature, this polar liquid is used as antifreeze, solvent, or fuel (e.g., in aeromodelling). Methanol is not present in large amounts in nature and is industrially produced. Methanol is mainly used as basic material for chemical synthesis of more complex chemical products. Nearly $40 \%$ of methanol is converted in formaldehyde to be then transformed into plastics, synthetic resins, paints, explosives, or fabrics. Methanol is a light liquid (specific gravity of 0.791 ), volatile (vapor pressure of $12.3 \mathrm{kPa}$ at $20{ }^{\circ} \mathrm{C}$ ), miscible in water, inflammable and toxic with a characteristic odor. These properties enable the classification of methanol as DE, a dissolving and evaporating substance.

If one considers only the SEBC classification, we can expect to monitor rapeseed oil (classified as floater $\mathrm{F}$ ), FAME (classified as floater F), toluene (classified as FE) and xylene (classified as FE) from radar remote sensing. For the last two, the speed of evaporation should be crucial. Thus, delays between releases and radar imagery must be short enough to allow efficient detection and analyses. For methanol and heptane, other remote sensing systems like infrared or ultraviolet sensors are expected to be more efficient [31].

During the POLLUPROOF experiment, $1 \mathrm{~m}^{3}$ of each of these six products was released at sea and imaged by radar and optical airborne sensors. Optical remote sensing results are beyond the scope of this paper and we focus here on SAR observations. Vegetal oils (like plant oil or rapeseed oil) have already been imaged by SAR sensors (plant oil is often used to simulate a natural monomolecular biogenic slick) and are observable in radar imagery [32]. Radar remote sensing of the five other HNS has not been as extensively studied as mineral or vegetal oils, especially in the case of experimental releases at sea, and we consider these in detail below.

\section{Planning of Measurements}

For the POLLUPROOF campaign, airborne multifrequency POLSAR acquisitions have been conducted over chemicals presented before (Section II-B) and discharged by the French Navy in the Mediterranean Sea. Experimentation took place in May 2015 over the French coast where three flights were performed, with two releases per flight:

The first flight took place on 18 May from 16:40 to 17:30 UTC. The sea was calm. Heptane and toluene were released from 2 semisubmersible $1 \mathrm{~m}^{3}$ tanks at 16:30 and 16:35 UTC, respectively. Heptane and toluene were released at known positions (separated by about $100 \mathrm{~m}$ ). SAR acquisitions began $10 \mathrm{~min}$ after the first release (heptane) and $5 \mathrm{~min}$ after the second release (toluene).

The second flight took place on 22 May from 13:25 to 13:55 UTC. There was a heavy swell, restricting any activity at sea, and hence products were discharged directly from the back 
TABLE I

ENVIRONMENTAL CONDITIONS

\begin{tabular}{cccccc}
\hline \hline Date & $\begin{array}{c}\text { TIME } \\
(\mathrm{UTC})\end{array}$ & $\begin{array}{c}\text { Wind } \\
\text { speed } \\
(\mathrm{m} / \mathrm{s})\end{array}$ & $\begin{array}{c}\text { Wind } \\
\text { direction } \\
\text { (from-deg) }\end{array}$ & $\begin{array}{c}\text { Wave } \\
\text { height } \\
(\mathrm{m})\end{array}$ & $\begin{array}{c}\text { Wave } \\
\text { direction } \\
\text { (from-deg) }\end{array}$ \\
\hline $\begin{array}{c}18 \text { may, } \\
2015\end{array}$ & $17: 00$ & 8 & 255 & 0.5 & 240 \\
22 may, & $13: 00$ & 7 & 315 & 2 & 270 \\
$\begin{array}{c}2015 \\
22 \text { may, } \\
2015\end{array}$ & $16: 00$ & 7 & 315 & 1.75 & 270 \\
\hline \hline
\end{tabular}

TABLE II

FLIGHT $n^{\circ} 1$ (18 MAY, 2015)

\begin{tabular}{ccc}
\hline \hline $\begin{array}{c}\text { Run } \\
\text { number }\end{array}$ & Time (UTC) & Radar look direction (deg) \\
\hline & $\mathbf{1 6 : 2 7}$ & Heptane release \\
& & \\
& $\mathbf{1 6 : 3 4}$ & Toluene release \\
& & $250^{\circ}$ \\
1 & $16: 40$ & $250^{\circ}$ \\
3 & $16: 48$ & $250^{\circ}$ \\
4 & $16: 57$ & $250^{\circ}$ \\
5 & $17: 06$ & $340^{\circ}$ \\
6 & $17: 16$ & $340^{\circ}$ \\
7 & $17: 25$ & $340^{\circ}$ \\
\hline \hline
\end{tabular}

TABLE III

FLIGHT $n^{\circ} 2$ (22 MAY, 2015)

\begin{tabular}{ccc}
\hline \hline $\begin{array}{c}\text { Run } \\
\text { number }\end{array}$ & Time (UTC) & Radar look direction (deg) \\
\hline & $\mathbf{1 2 : 3 5 - 1 2 : 4 6}$ & Methanol release \\
& $\mathbf{1 2 : 5 3 - 1 3 : 2 5}$ & Xylene release \\
& $13: 25$ & $270^{\circ}$ \\
1 & $\mathbf{1 3 : 2 9}$ & $\mathbf{0}^{\circ}$ \\
$\mathbf{2}$ & $13: 36$ & $180^{\circ}$ \\
3 & $13: 45$ & $270^{\circ}$ \\
4 & $13: 56$ & $180^{\circ}$ \\
5
\end{tabular}

of the boat (French Navy) advancing toward the east at a speed of 1 knot. Methanol was released from 12:35 to 12:45 UTC and xylene from 12:55 to 13:25 UTC. SAR acquisitions began $40 \mathrm{~min}$ after the end of the first release (methanol) and at the end of the second release (xylene).

The third flight took place on 22 May from 15:20 to 16:50 UTC. Because of the swell, products were also released directly from the back of the boat advancing toward the east at a speed of 1 knot. Rapeseed oil was discharged from 15:00 to 15:30 UTC and FAME from 15:25 to 15:40 UTC. SAR acquisitions were synchronized with releases.

Sea and weather conditions during experimentation are presented in Table I. A description of each run of SAR acquisition is given in Tables II-IV (Flights 1-3), respectively. In Tables III-IV, the lines in bold correspond to the
TABLE IV

FLIGHT $n^{\circ} 3$ (22 MAY, 2015)

\begin{tabular}{ccc}
\hline \hline $\begin{array}{c}\text { Run } \\
\text { number }\end{array}$ & Time (UTC) & Radar look direction (deg) \\
\hline & $\mathbf{1 5 : 0 1 - 1 5 : 2 8}$ & Rapeseed oil release \\
& $\mathbf{1 5 : 2 4 - 1 5 : 4 0}$ & FAME release \\
& $15: 22$ & $270^{\circ}$ \\
1 & $15: 33$ & $270^{\circ}$ \\
2 & $15: 43$ & $270^{\circ}$ \\
3 & $15: 56$ & $270^{\circ}$ \\
4 & $\mathbf{1 6 : 0 7}$ & $\mathbf{1 8 0}^{\circ}$ \\
$\mathbf{5}$ & $16: 20$ & $180^{\circ}$ \\
6 & $16: 33$ & $0^{\circ}$ \\
7 & $16: 43$ & $315^{\circ}$ \\
8 & $16: 49$ & $270^{\circ}$ \\
9 & & \\
\hline \hline
\end{tabular}

acquisitions mainly analyzed in the following. In this paper, we focus on cross-wind observation because in this case the spill is well centered in the image, oriented parallel to the azimuth axes. For upwind or downwind acquisitions, the spill is across the swath and variations with incidence angle can add other effects. Note that sea conditions are not exactly the same for Flight 1 and for Flights 2 and 3. Due to weather conditions, methods of release also differ between Flight 1 and Flights 2 and 3. Since each chemical was released only once and since each spilled product is different from one flight to each other's, in this paper monitoring of HNS is studied regardless of sea conditions.

\section{Methodology}

\section{A. Scattering From Ocean Surface}

Ocean surfaces can be modeled as a composition of slightly rough tilted facets, each of which has superimposed smallscale surface roughness that creates a Bragg scattering [8]. Small-scale roughness is randomly distributed on the scattering surface and responds to the strength of local wind, i.e., gravity capillary waves, whose wavelength is of order centimeters to decimeters with periods less than $1 \mathrm{~s}$ [33]. The tilt of the facet is caused by larger scale gravity waves on the ocean surface that changes the local orientation, or tilt, of the short waves [34]. The orientation of the facet normal in the radar reference frame is defined by two angles $\psi$, which is the angle between local up and the projection of the facet normal onto the radar scattering plane, and $\xi$, the angle between local up and the projection of the facet normal onto the vertically oriented plane perpendicular to the scattering plane [35]. The resulting local incidence angle of the EM wave is

$$
\theta_{i}=\cos ^{-1}[\cos (\theta+\psi) \cos \xi]
$$

where $\theta$ is the EM angle of incidence relative to local untilted up. The copolarized radar backscattered power is proportional to the normalized radar cross section (NRCS), which is defined as [8]

$$
\sigma_{p p}^{0}=4 \pi k_{E M}^{4} \cos ^{4} \theta_{i} \Gamma_{p p} W
$$


where the subscript $p$ denotes either $\mathrm{H}$ (horizontal) or $\mathrm{V}$ (vertical) polarization, $\mathrm{k}_{\mathrm{EM}}=2 \pi / \lambda_{\mathrm{EM}}$ is the $\mathrm{EM}$ wavenumber corresponding to wavelength $\lambda_{\mathrm{EM}}, W$ is the spectral density of the ocean surface roughness, and $\Gamma_{\mathrm{pp}}$ is the reflectivity. The spectral density of the ocean surface describes the shape or directionality of the radar signal scattered by the ocean surface [21], while the reflectivity describes the total power scattered from the surface. Copolarized reflectivity is a function of the facet tilt, EM wave incidence angle, and the electrical properties of the seawater such that

$$
\Gamma_{p p}=\left|\left(\frac{\sin (\theta+\psi) \cos \xi}{\sin \theta_{i}}\right)^{2} \alpha_{p p}+\left(\frac{\sin \xi}{\sin \theta_{i}}\right)^{2} \alpha_{q q}\right|^{2}
$$

where the subscript $p(p \neq q)$ denotes either $\mathrm{H}$ or $\mathrm{V}$ polarization. The Bragg scattering coefficients, defined as [8]

$$
\begin{aligned}
\alpha_{H H} & =\frac{\cos \theta_{i}-\sqrt{\varepsilon_{r}-\sin ^{2} \theta_{i}}}{\cos \theta_{i}+\sqrt{\varepsilon_{r}-\sin ^{2} \theta_{i}}} \\
\alpha_{V V} & =\frac{\left(\varepsilon_{r}-1\right)\left(\sin ^{2} \theta_{i}-\varepsilon_{r}\left(1+\sin ^{2} \theta_{i}\right)\right)}{\left(\varepsilon_{r} \cos \theta_{i}+\sqrt{\varepsilon_{r}-\sin ^{2} \theta_{i}}\right)^{2}}
\end{aligned}
$$

depend only on the local incidence angle of the EM wave $\theta_{i}$ and the relative dielectric constant $\varepsilon_{r}$. For a given viewing geometry (fixed incidence angle) and assuming that the ocean surface is homogeneous over a sufficiently large area, the NRCS is a function of only the EM wavelength, the relative dielectric constant and the sea surface roughness.

In the case of an ocean surface covered by slicks, the product surface layer will damp the gravity-capillary waves, thereby attenuating the radar backscattered power. The relative dielectric constant can also be reduced in the case of a product that is mixed with seawater, because the relative dielectric constant of released product is low compared to seawater. See [35] in the case of oils and dielectric properties of HNS studied during the experiment have been measured to be similar of those of oil (authors are not allowed to publish the actual values). The resulting NRCS will be lower for a product mixed with water than for clean sea surface.

This study is based on the principle that in the case of a thin layer, only the short gravity-capillary waves will be damped. When the layer gets thicker, longer gravity capillary waves should also be damped (see Figs. 1 and 3 [36]). These phenomena should be observable in the case of multifrequency SAR data acquired simultaneously over the same surface. Moreover, this should be enhanced when using sufficiently different EM wavelengths (e.g., X- and L-band) since the EM signal will simultaneously interact with hydrodynamic mechanisms of different scales.

From the above model of the sea surface and interactions with the EM signal, we propose two methods. The first method allows for detection and relative quantification of the impact of a released product on the ocean surface (Section III-B). The second method allows for characterization of the behavior of the involved substance discharged in the marine environment (Section III-C).

\section{B. Detection and Relative Quantification}

Many studies have suggested using POLSAR parameters to improve slick detection capability. A useful review of those parameters has been proposed in [11], wherein most of the methods published in the literature for oil slicks detection are presented. A comprehensive comparison of those parameters was undertaken in [37]. Following [38], [37] quantitatively demonstrates the effectiveness of the polarization difference (PD) for oil slick detection on the ocean surface. $\mathrm{PD}$ is defined such as

$$
\mathrm{PD}=\sigma_{V V}^{0}-\sigma_{H H}^{0}
$$

where $\sigma_{P P}^{0}$ is the NRCS (in linear units) and the subscript $p$ denotes either $\mathrm{H}$ or $\mathrm{V}$ polarization.

The interest in this parameter for a marine pollutant detection application is that PD is proportional to the spectral density of the ocean surface roughness $W$ [39]. As discussed in [38] and [40], the nonpolarized part of the backscattered signal is removed using PD, and thus it mostly contains contribution due to short wind waves around the Bragg wavenumber. This is precisely the scale of waves that will be mainly affected by the presence of a liquid substance on the sea surface; which makes PD an attractive parameter for slick detection at sea [38]. To enhance its use, we propose in this paper a normalized variant of PD. We note that PD ranges from a maximum value that occurs in the case of a clean sea surface $\left(\mathrm{PD}_{\text {water }}\right)$ and goes to 0 as the impact of the substance on the surface increases, since both $\mathrm{VV}$ and $\mathrm{HH}$ reflectivity tend to 0 over a perfectly smooth surface. Hence, we define the normalized PD (NPD) as

$$
\mathrm{NPD}=1-\frac{\mathrm{PD}}{\mathrm{PD}_{\text {water }}} \quad 0 \leq \mathrm{NPD} \leq 1 .
$$

Following (2) and (6), NPD can be written in terms of spectral density and reflectivity as

$$
\mathrm{NPD}=1-\frac{W^{\text {slick }}\left(\Gamma_{V V}^{\text {slick }}-\Gamma_{H H}^{\text {slick }}\right)}{W^{\text {water }}\left(\Gamma_{V V}^{\text {water }}-\Gamma_{H H}^{\text {water }}\right)}
$$

where superscripts water and slick correspond to uncontaminated and contaminated water, respectively. The NPD depends on two contrasts between contaminated and uncontaminated water, one contrast on the spectral density of the surface $(W)$, which is driven by the difference of roughness between the two surfaces, and the other on the polarimetric reflectivity difference. Assuming that the tilt angles are constant regardless of the presence of slick [41], the latter contrast depends on the difference in the dielectric constant between the clean sea surface and the polluted water. NPD is equal to 0 over clean sea area and goes to 1 as the concentration or the impact of the product on the ocean increases. Hence, NPD can be interpreted as an indication of the presence and the relative concentration of a substance on the sea surface. It can be used directly or with a threshold to produce a binary detection map. Therefore, a detection map and a relative quantification map can be computed simultaneously based on NPD. This information is valuable for both identifying polluted sea surfaces and locating the most contaminated areas, thus guiding cleaning operations. 

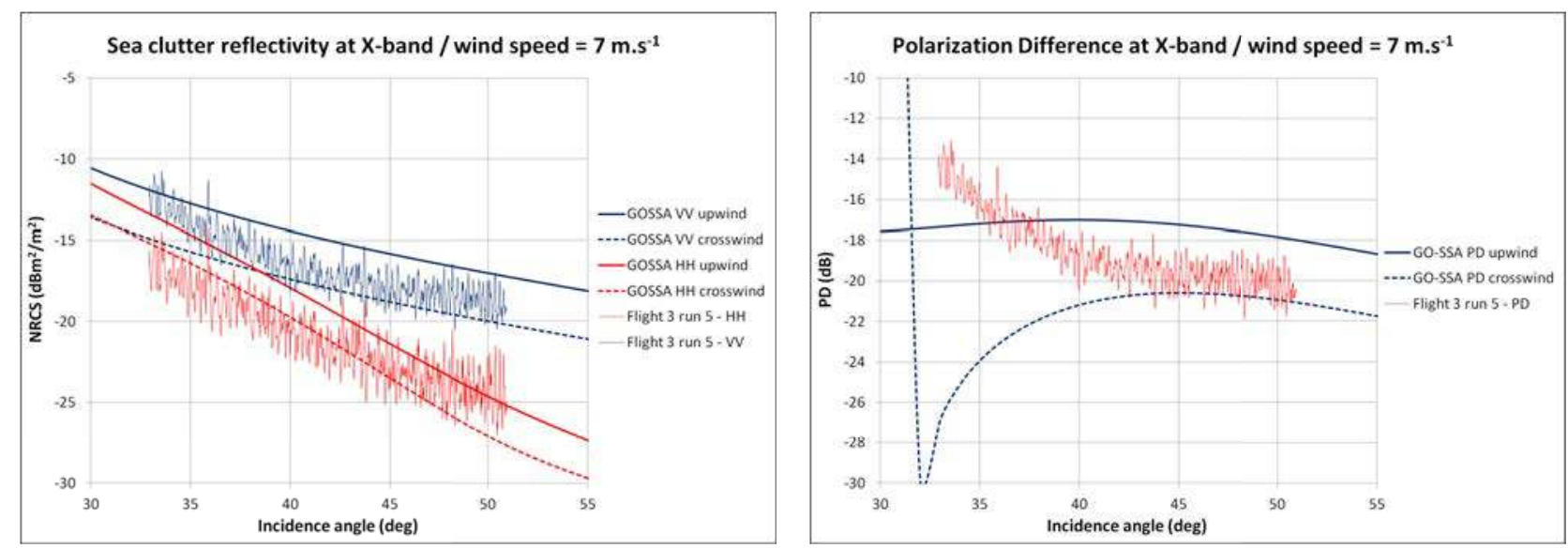

X-band: sea clutter reflectivity (left) and Polarization Difference (right)
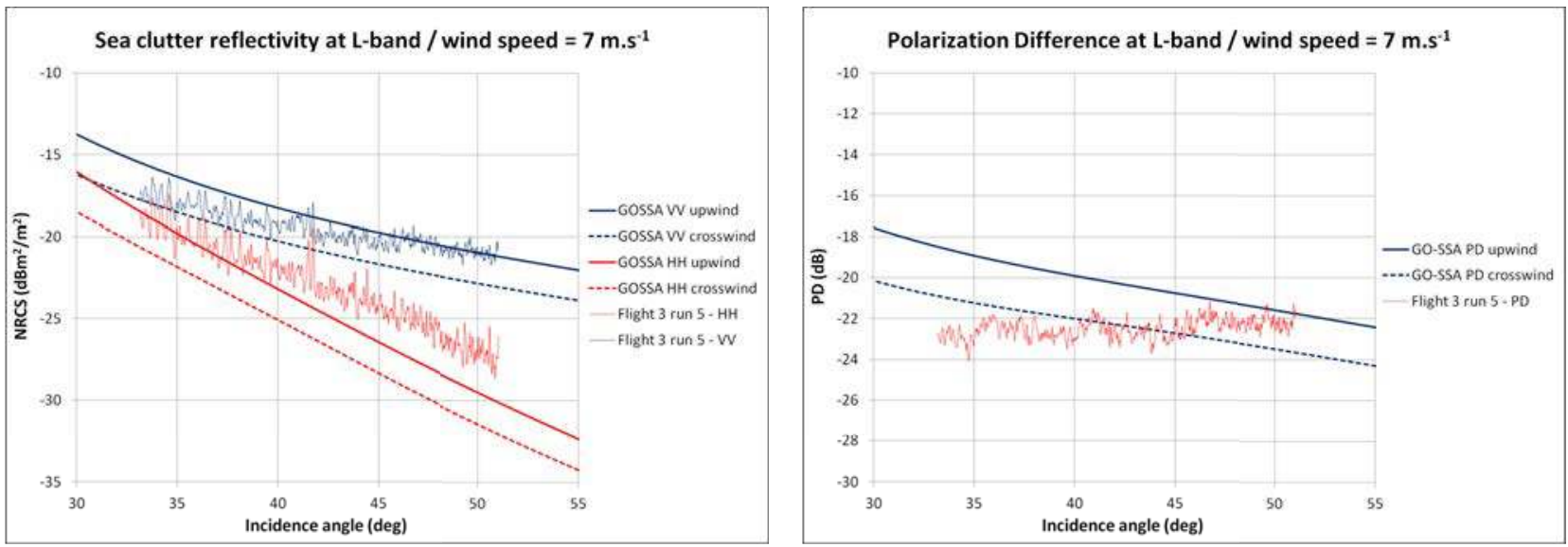

L-band: sea clutter reflectivity (left) and Polarization Difference (right)

Fig. 1. Comparison between the measured and theoretical sea clutter reflectivities (left) and PD (right) at X-band (top) and L-band (bottom).

In (7), $\mathrm{PD}_{\text {water }}$ is the $\mathrm{PD}$ value obtained in the case of a clean sea surface. It can be computed directly from the dual copolarized channels (HH and VV) over uncontaminated area of water imaged by the radar, most likely selected by visual inspection. If an automatic process is needed, $\mathrm{PD}_{\text {water }}$ can be estimated through a model. This latter method requires only wind speed and wind direction information, but uncertainties induced by the chosen model and the meteorological parameters can introduce some differences between the estimated and the measured $\mathrm{PD}_{\text {water }}$ values. The selection of the model should be done judiciously and in the following, the GO-SSA physical two-scale model [42] is used to estimate the PD over clean sea surface with the wind information given in Table I.

A comparison between theoretical values obtained with the GO-SSA model and values measured over uncontaminated areas of SAR data are shown in Fig. 1. Experimental data used for this comparison were acquired during the third flight for a crosswind observation (fifth run). The PD values are plotted in decibel scale to enhance interpretation. We can observe an overall agreement between the physical two-scale model and experimental measurements, especially at X-band. At L-band, estimated values are slightly lower than measured, and so estimated $\mathrm{PD}_{\text {water }}$ is underestimated by only 1 or $2 \mathrm{~dB}$. We assume that this difference is due to the presence of a strong swell, not taken into account in the GO-SSA model, with a stronger effect at low frequency than at high frequency. Nevertheless, those discrepancies will weakly impact the exploitation of the data while making it more automatic, since it does not require manual selection of a clean sea area through the entire swath of an image.

\section{Characterization}

When a pollutant spills into a marine environment, the selection of the appropriate response requires detailed knowledge of the physical and chemical properties of the involved substance. It has been demonstrated in [41] that for the case of an oilrelated offshore pollutant, SAR imagery can indicate whether the spilled product behaves like a viscoelastic film that is more or less homogenous and floating on the surface or if the spilled product is mixed with seawater within the upper few centimeters of the water column. The basic premise of this method, which yields the oil-water mixing index $(M)$, is that radar backscattered power is diminished by oil slicks through 
mechanical damping of Bragg wavelength gravity capillary waves and reductions in the relative dielectric constant of the upper few centimeters near the sea surface [35], [41]. By decoupling the relative contribution to signal attenuation of mechanical damping of surface roughness and changes in dielectric constant, we can define the characteristics of the slick along a spectrum ranging from thin surface films to a product mixed with seawater within the water column [41].

In addition to the assumptions underlying the NRCS model (2), the process of decoupling the mechanical and EM attenuation mechanisms is based on the following assumptions.

1) The long-wavelength tilting of the sea surface [as described by angles $\psi$ and $\xi$ in (1)] is unaffected by the presence of an oil slick [35].

2) The dielectric constant of uncontaminated seawater is well constrained [21].

These assumptions allow for inferences of the long-wavelength tilting of the sea surface over the entire radar image (so long as the radar images ample areas of uncontaminated water), the dielectric constant of contaminated water, and the smallscale roughness spectrum of both contaminated and uncontaminated water. As described in detail in [41], the salient parts of the process of decoupling the mechanical and EM attenuation mechanisms can be summarized as follows.

1) Use the copolarized ratio over uncontaminated seawater and an assumed value for the dielectric constant of pure seawater, $\varepsilon_{r}^{\text {water }}$, to infer the long-wavelength tilting of the ocean surface. In the following, $\varepsilon_{r}^{\text {water }}$ is taken to be $80-\mathrm{i} 70$ [21].

2) Calculate the short-wavelength roughness spectrum over uncontaminated water, $W^{\text {water }}$, by applying the tilt angles estimated in 1).

3) For each pixel of contaminated water, infer the local (effective) relative dielectric constant, $\varepsilon_{r}^{\text {slick }}$, from the copolarized ratio and the estimated long-wavelength tilt angles deduced from 1).

4) Calculate the short-wavelength roughness spectrum over contaminated water, $W^{\text {slick }}$, using the dielectric constant inferred in 3) and the tilt angles obtained in 1).

Once 1)-4) are complete, we can calculate $M$ as

$$
M=M_{W}-M_{\alpha}
$$

where

$$
\begin{aligned}
M_{W} & =\frac{W^{\text {water }}-W^{\text {slick }}}{W^{\text {water }}} \\
M_{\alpha} & =\frac{\left|\alpha_{V V}^{\text {water }}\right|^{2}-\left|\alpha_{V V}^{\text {slick }}\right|^{2}}{\left|\alpha_{V V}^{\text {water }}\right|^{2}} .
\end{aligned}
$$

$M_{W}\left(0 \leq M_{W} \leq 1\right)$ is the normalized damping factor and $M_{\alpha}$ $\left(0 \leq M_{\alpha} \leq 1\right)$ is the normalized power attenuation factor. $M_{W}$ is a measure of how much the product will damp the sea surface roughness $(0$ indicates no damping and 1 indicates total damping), while $M_{\alpha}$ is a measure of how much the backscattered signal is attenuated due to a lower relative dielectric constant ( 0 indicates no attenuation and 1 indicates total attenuation).
$M(-1 \leq M \leq 1)$ is the oil-water mixing index introduced in [41] that we will apply here in the case of HNS-related incident. Negative values indicate that reduced EM amplitudes are due more to reduced relative dielectric constants than to damped surface roughness, meaning that the product is largely mixed with seawater. On the other hand, positive values indicate that the decreasing of the EM signal is mainly due to smoothing of the ocean surface, and thus product is primarily present as a film on the sea surface. In an operational context, this information may be valuable to identify the behavior of the pollutant and guide response activities.

\section{RESUlTS AND Discussion}

We applied the methodologies described in the previous section to identify and characterize HNS released during the POLLUPROOF experiment. We first analyze which of the six chemicals discharged are detectable with radar imagery. Then we discuss the efficiency of multifrequency POLSAR imagery for HNS-related maritime pollution monitoring.

\section{A. Observation of Hazardous and Noxious Substances at Sea}

During the first data acquisitions, heptane and toluene were discharged at sea and the slick areas were imaged by SETHI. Neither chemical was detected in SAR acquisitions at either $\mathrm{X}$-band or L-band. The lack of radar detection is likely due to the extreme volatility of heptane and toluene. As previously noted, heptane and toluene were released only 5 and $10 \mathrm{~min}$ before acquisitions, and despite the short time lag between discharge and measure, it is likely that evaporation is important enough so that the chemicals are not observed in SAR imagery.

Methanol was released during the second exercise. Given that methanol is both extremely volatile substance and soluble in water and that SAR imagery occurred $40 \mathrm{~min}$ after the end of its release, methanol was never observed in SAR acquisitions at either X-band or L-band.

SAR observations collected over released xylene show that this chemical is observable as an area of reduced amplitude on SAR images (Fig. 2). As for oil, the contrast is enhanced using VV polarization compared with HH (not shown here) and the impact of the product is more pronounced at X-band than at L-band. The approximate area extent of the spill was $0.26 \mathrm{~km}^{2}$, and the bright point just at the end of the spill is the ship $(53 \mathrm{~m}$ length) from which the discharges were performed. One can observe a strong impact of xylene on the sea surface imaged at X-band. At L-band, the slick is not easily observable, probably due to a low effect of this HNS on the sea surface damping only short gravity capillary waves corresponding mainly to the X-band Bragg wavelength. SAR images over xylene were acquired up to $30 \mathrm{~min}$ after the end of the release and the HNS is still observable even on the later acquisition. Both toluene and xylene are classified as floating and evaporating FE substance according to the SEBC classification. However, toluene (whose vapor pressure at $20{ }^{\circ} \mathrm{C}$ is $2.91 \mathrm{kPa}$ ) was not observed (SAR imagery started $40 \mathrm{~min}$ after the end of the release), while xylene (whose vapor pressure at $20{ }^{\circ} \mathrm{C}$ is $0.89 \mathrm{kPa}$ ) is detectable on all SAR data, acquired up to $30 \mathrm{~min}$ after the end of the release. 


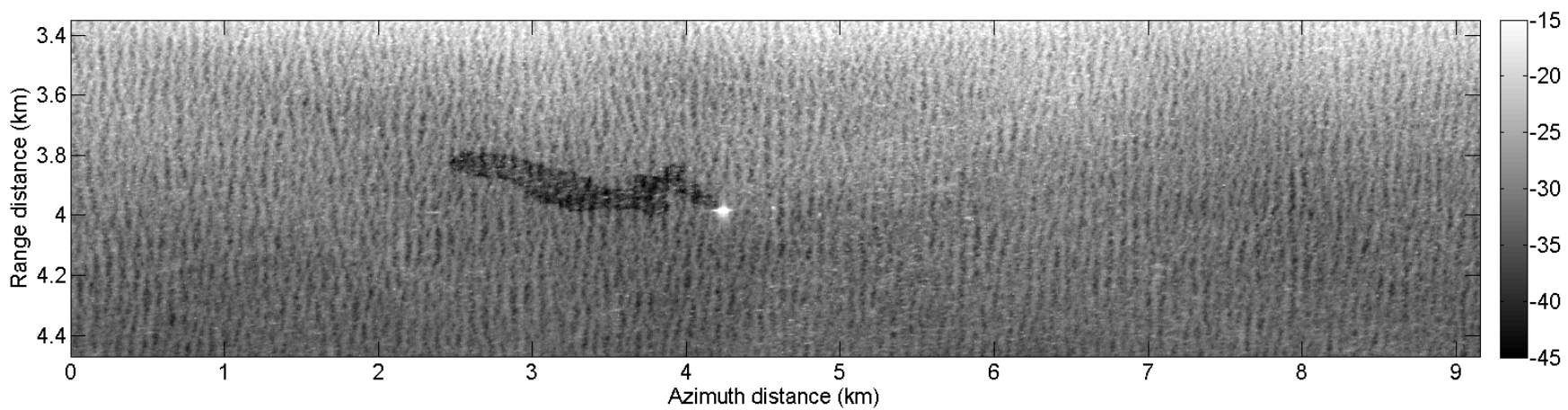

(a)

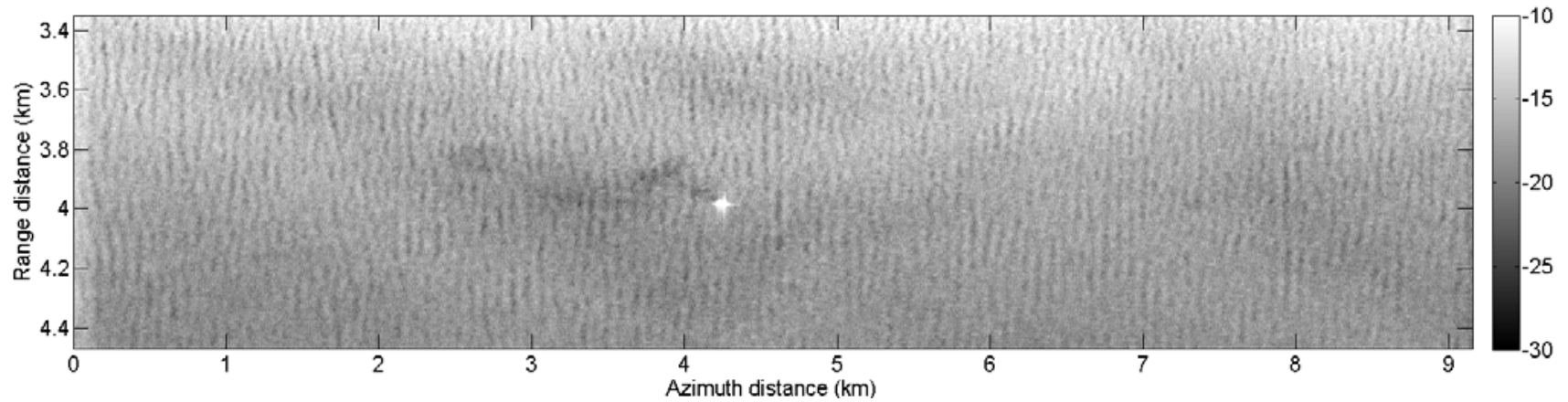

(b)

Fig. 2. SAR images over xylene for (a) X-VV and (b) L-VV taken on May 22, 2015 at 13:29 UTC (multilook $7 \times 7$ ), crosswind observation.

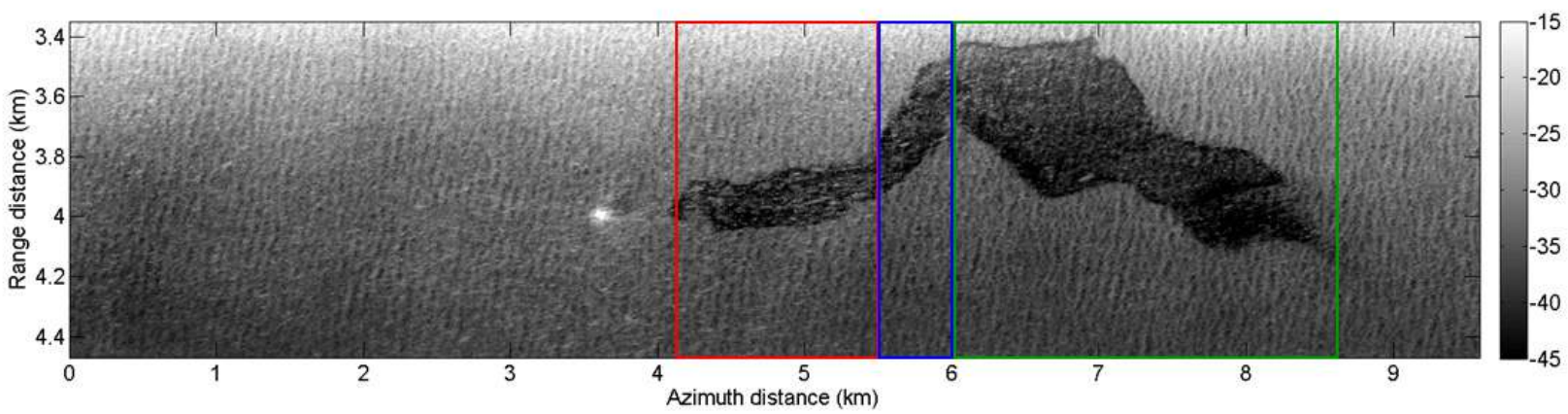

(a)

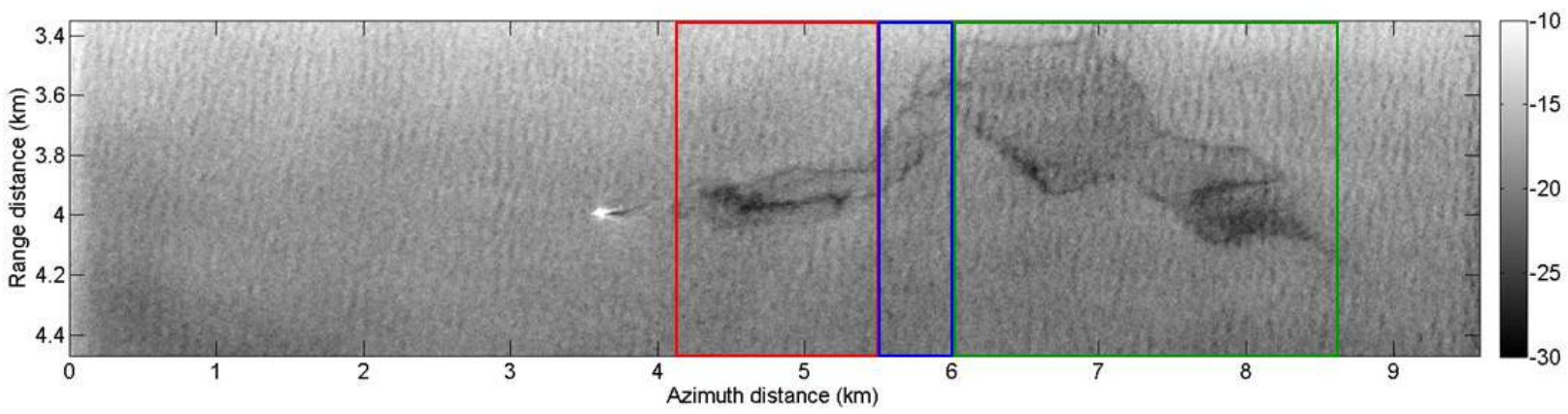

(b)

Fig. 3. SAR images over rapeseed oil and FAME for (a) X-VV and (b) L-VV taken on May 22, 2015 at 16:07 UTC (multilook 7 $\times 7$ ), crosswind observation. FAME is indicated by the red box, rapeseed oil by the green box, and the blue box corresponds to a mixture between the two chemicals.

SEBC enables only a first estimation of chemical behaviors, here it is observed that a priori detection of HNS using SAR remote sensing cannot be based only on this classification, the importance of the evaporation rate of a chemical when monitored by remote sensing is also a key parameter.

The two more persistent HNS, classified as a floater $F$ in the SEBC, have been studied during the last flight. Both rapeseed oil and FAME are observable on SAR images acquired at $\mathrm{X}$ - and L-band. VV polarized images for crosswind observation over the two releases forming a single spill are shown (Fig. 3). Data have been acquired at 16:07 UTC, namely, $40 \mathrm{~min}$ after the end of the rapeseed oil release and $30 \mathrm{~min}$ after the FAME release. Rapeseed oil, having been discharged first, corresponds to the right part of the spill while FAME to 


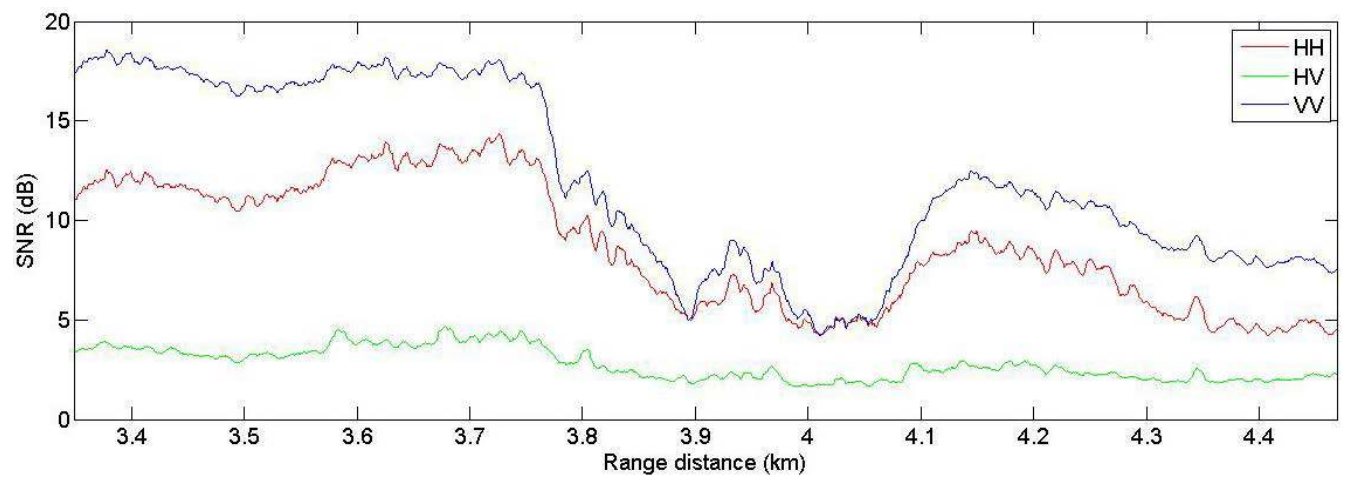

(a)

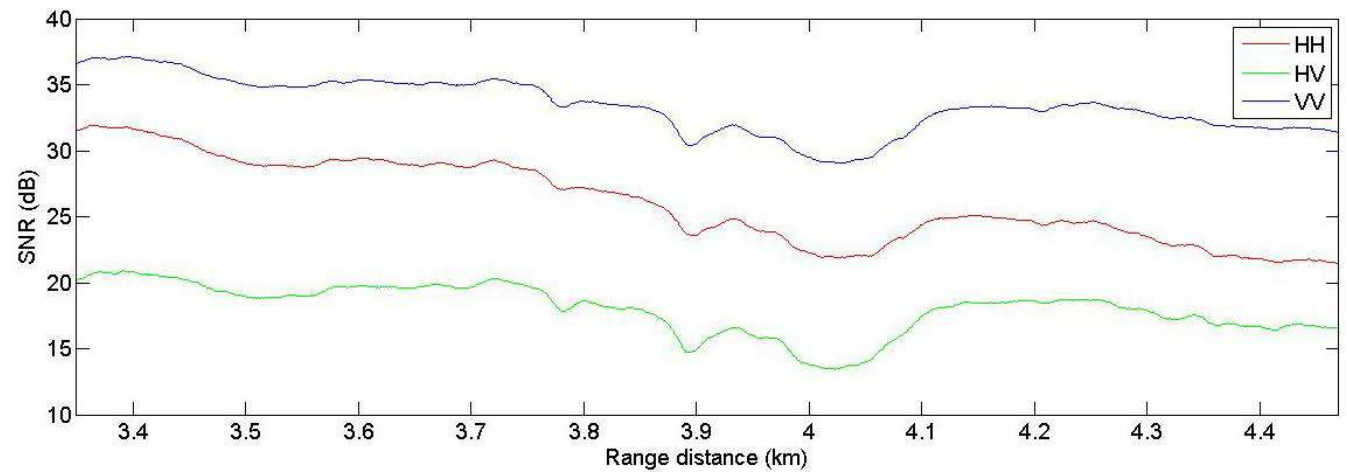

(b)

Fig. 4. SNR at X-band (a) and L-band (b) for polarization HH (red curve), HV (green curve), and VV (blue curve) taken on May 22, 2015 at 16:07 UTC. Range transect for azimuth $8 \mathrm{~km}$ (see Fig. 3).

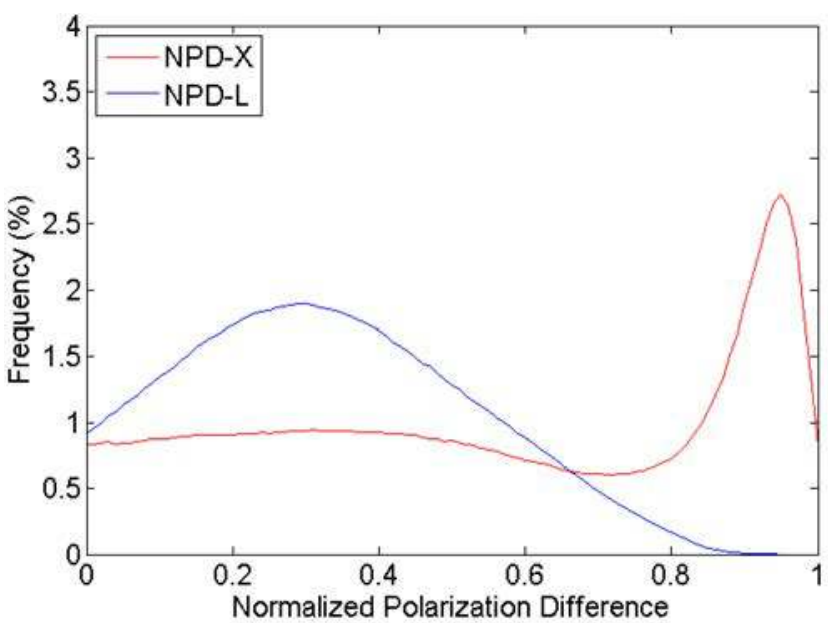

Fig. 5. Histograms of NPD at X-band (red curve) and L-band (blue curve) over full area (uncontaminated and contaminated seawater).

the left. The overall surface of the spill is $1.745 \mathrm{~km}^{2}$. From in situ information, we know that FAME ranges from azimuth 4100 to $5500 \mathrm{~m}$ (covering a surface of $0.29 \mathrm{~km}^{2}$; see the red box in Fig. 3), and that rapeseed oil is from azimuth 6000 to $8500 \mathrm{~m}$ (which corresponds to a surface of $1.26 \mathrm{~km}^{2}$; see the green box in Fig. 3). In between, we have a mixture of the two products (surface of $0.195 \mathrm{~km}^{2}$; see the blue box in Fig. 3). These amplitude images do not allow us to distinguish the two chemicals that form the spill because their respective impact on the backscattered signal appears similar, in terms of amplitude.

The SNRs computed for SAR data acquired during the third flight (run 5 at 16:07 UTC) are shown in Fig. 4. The range

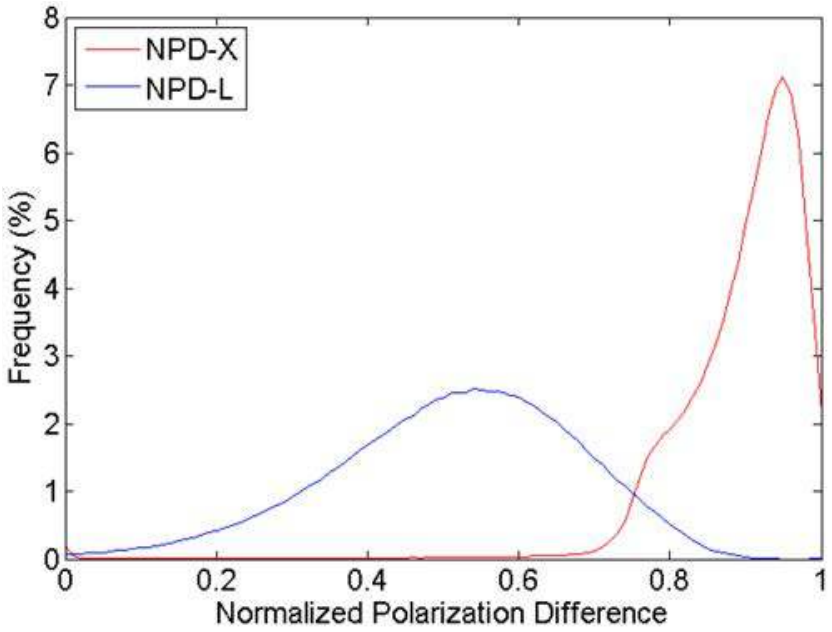

Fig. 6. Histograms of NPD at X-band (red curve) and L-band (blue curve) over contaminated seawater.

transect is computed for the azimuth $8000 \mathrm{~m}$; the spill is between range 3750 and $4100 \mathrm{~m}$ (see Fig. 3). For polarization $\mathrm{HH}$ and VV, the SNR is greater than $5 \mathrm{~dB}$ at X-band and $20 \mathrm{~dB}$ at L-band. This allows for an efficient analysis of copolarized channels, even over polluted areas, for both frequency bands. Note that the SNR for the cross polarization at L-band is also very high.

The HV channel is never used in this paper, but the high value of SNR suggests interesting perspectives for the exploitation of the cross polarization. 


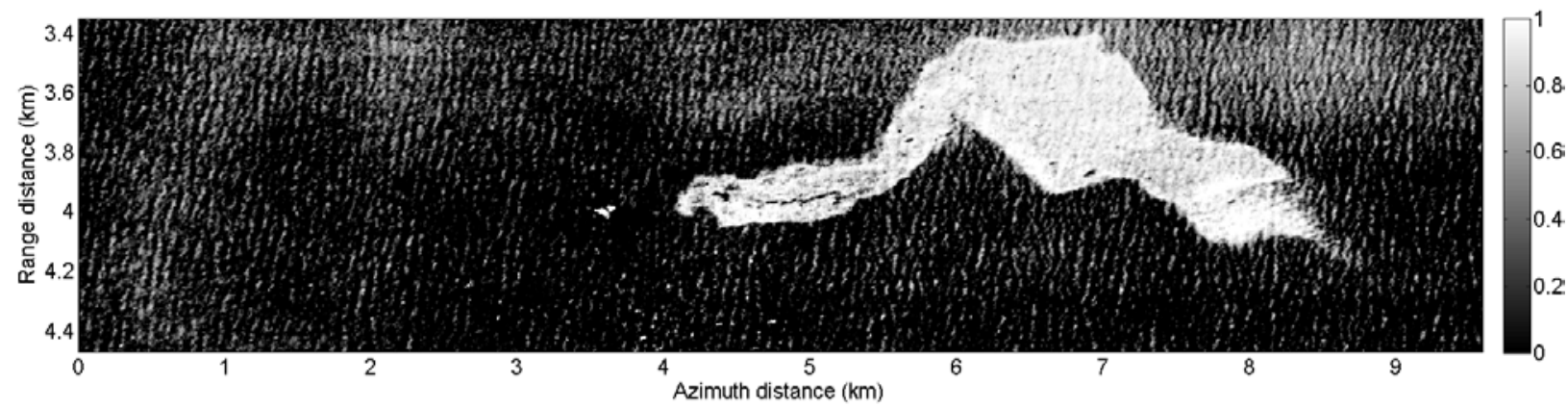

(a)

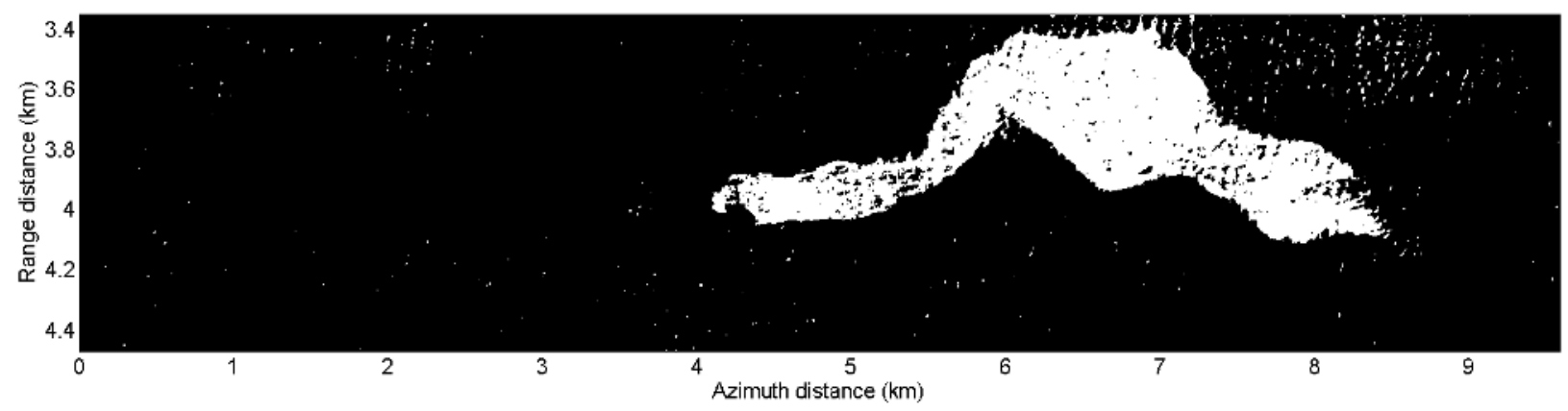

(b)

Fig. 7. NPD at (a) X-band and (b) detection mask taken on May 22, 2015 at 16:07 UTC for FAME and rapeseed oil (multilook $7 \times 7)$, crosswind observation.

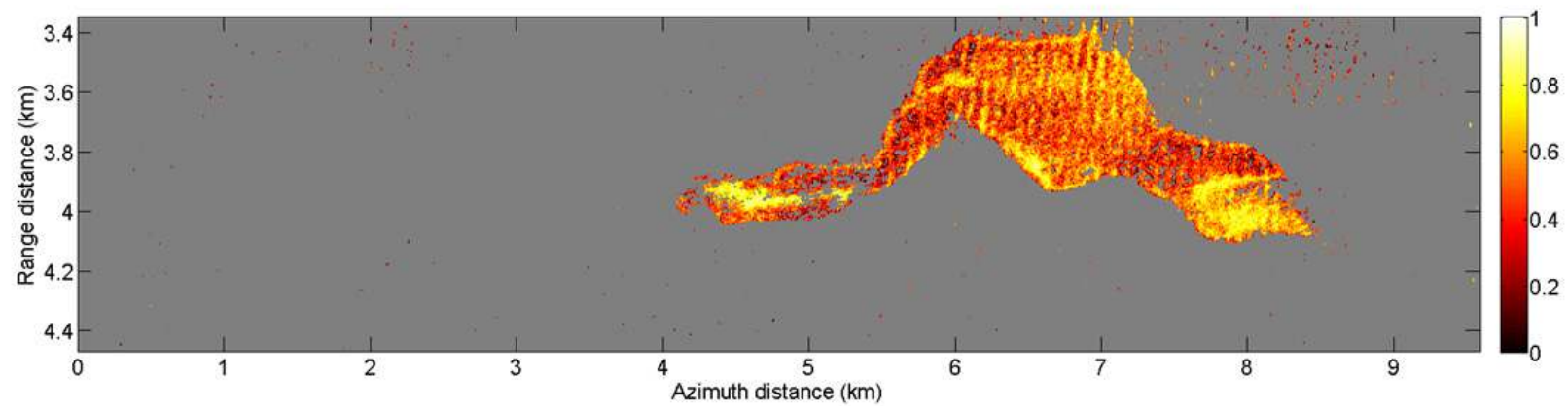

Fig. 8. NPD at L-band taken on May 22, 2015 at 16:07 UTC for FAME and rapeseed oil (multilook $7 \times 7$ ).

At X-band polarization VV, we measure a contrast of $5-10 \mathrm{~dB}$ between pure seawater and sea polluted by HNS, while at L-band, the contrast is lower than $5 \mathrm{~dB}$. Contrast between the spill and the clean sea surface is more significant at X-band than at L-band, which support the use of high frequencies compared with low frequencies for maritime pollution monitoring [9], even in the case of HNS-related incident. While at X-band, the spill seems homogeneous [Fig. 3(a)], at L-band [Fig. 3(b)], we observe strong variations of the EM signal into the spill with dark patches. We can assume that short gravity capillary waves, corresponding to the $\mathrm{X}$-band Bragg wavelength, are more or less damped anywhere within the spill, which implies, at this wavelength, a uniformly low response over the contaminated area. At L-band, the spill looks heterogeneous and a high SNR allows us to identify areas within the spill where HNS as a stronger impact than elsewhere, probably due to a higher concentration of the chemical. These observations support previous results [9], [43] and the NRCS model, which all show that the characteristics of EM backscatter over contaminated seawater are wavelength dependent. Thus by using different frequency bands, we should be able to better characterize the contaminant.

\section{B. Detection and Quantification of Impact on the Ocean Surface}

We now undertake a quantitative study of the added value of multifrequency POLSAR imagery for monitoring chemical pollution at sea. As presented in Section III-B and based on previous work done about oil-related incident, the NPD is proposed to detect HNS at sea and quantify their relative concentration on the ocean surface.

Histograms of NPD values at X- and L-band computed over data acquired during the last flight (FAME and rapeseed oil releases) are shown in Figs. 5 and 6 (histograms obtained over the entire image scene and histograms computed only over the contaminated area), respectively. At X-band (see the red curve in Fig. 5), the histogram shown in Fig. 5 has a strong maximum at 0.95 , corresponding to seawater contaminated by FAME or rapeseed oil. Lower values are those of 


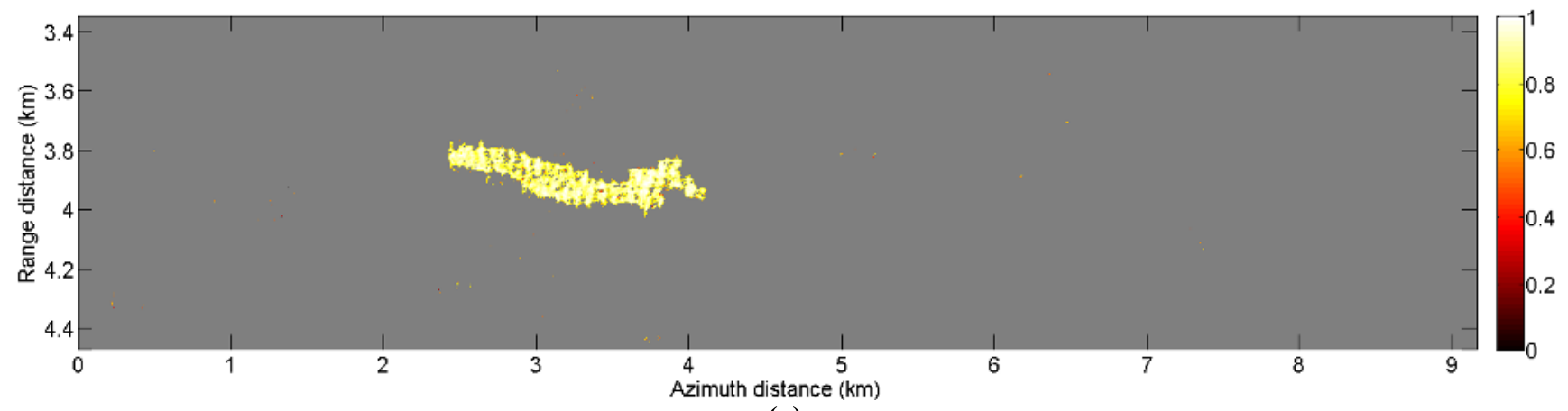

(a)

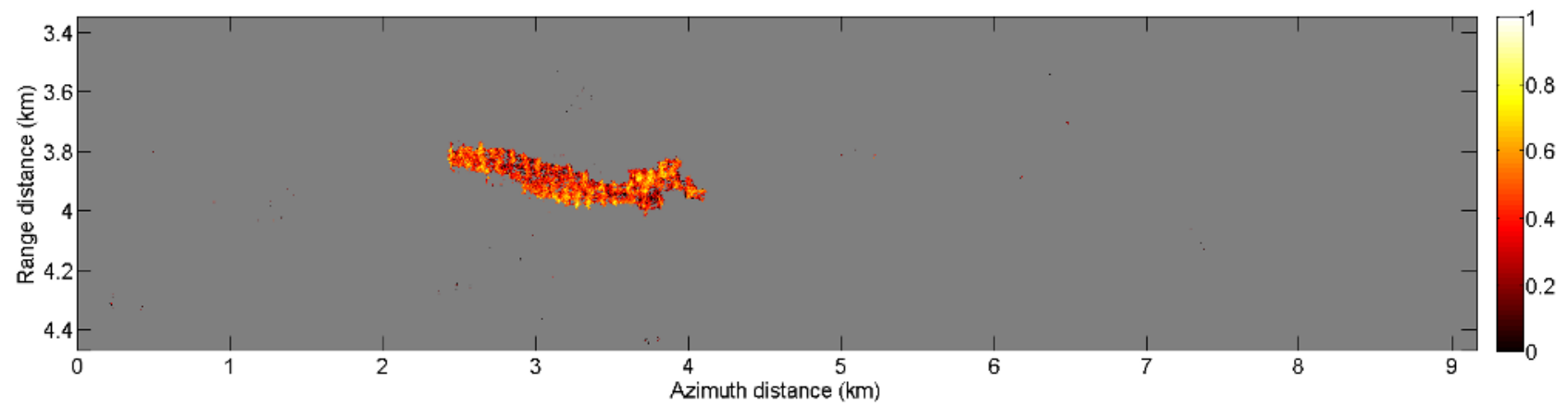

(b)

Fig. 9. NPD at (a) X-band and (b) L-band taken on May 22, 2015 at 13:29 UTC for xylene (multilook $7 \times 7$ ), crosswind observation.

clean seawater (see the red curve in Fig. 5). The distinction between slick and slick-free areas is thus clear. Interestingly, at L-band (see the blue curve in Fig. 6), one can observe more variation of the NPD parameter within the spill, with values ranging mainly from 0.2 to 0.8 . These variations make detecting HNS more challenging with L-band than with Xband but suggest that with a sufficiently high SNR and with a well-adapted frequency, EM signal allows for measurements of the relative impact of product within the spill. This impact should be related to the concentration of product.

From these observations, the proposed method to detect and relatively quantify maritime pollution is as follows.

1) First, a detection mask is calculated by thresholding the NPD map at X-band.

2) Then, the L-band NPD parameter is computed over detected pixels from the previous step.

This methodology was applied on data acquired during the releases of FAME and rapeseed oil (third flight). The NPD map at X-band and the detection mask obtained by thresholding the NDP values at $X$-band for values greater than 0.7 are shown in Fig. 7. The empirical value of 0.7 was manually chosen from the results obtained with this experiment. Automatic selection of a threshold is a subject for future studies. The ship, from which the discharges were performed, has been filtered by thresholding the copolar phase, assumed to be null over sea surface and nonzero over ships. The NPD map at L-band, to which the detection mask is applied, is shown in Fig. 8. One can observe that the spill is well detected using this method. A wave pattern is observable in the upper part of the rapeseed oil spill, which corresponds to the impact of the swell on the radar reflectivity (Fig. 3) and should not be interpreted as a local variation of the HNS concentration. On the other hand, an evolution of the concentration is clearly observable on the right part of the spill (range: 7.2$8.5 \mathrm{~km}$ ). Then, we can observe that information provided by the two frequencies is effectively different: at X-band values of NPD within the spill are almost always close to 1.0 (between 0.8 and 1.0), whereas at L-band, much more fluctuations are observed. Similar results are obtained with $\mathrm{X}$ - and L-band SAR data acquired over xylene release (Fig. 9). At X-band, response is saturated by the presence of the liquid substance. This frequency is perfectly suited for detection but does not seem to provide information on the thickness (for the SNR with which SAR data were acquired). At lower frequency (L-band in our case), the EM signal backscattered by the spill fluctuates with the concentration of the HNS within the contaminated area. Information provided by NPD and simultaneous use of two frequency bands allow us to detect HNS at sea and to quantify their impact on the ocean surface in terms of relative concentration. However, results shown in Fig. 8 do not enable us to distinguish between the two products that form the spill (rapeseed oil and FAME). The oil-water mixing index $(M)$ is then required to achieve this.

\section{Characterization}

In the third exercise, two chemicals were successively discharged: rapeseed oil and FAME, forming a single spill. The right part of the spill is rapeseed oil and the left part is FAME. Both products are classified as floater $\mathrm{F}$ in the SEBC, but from the physical and chemical properties of each HNS (see Section II-B), one can expect different behaviors of each product on the sea surface. Indeed, rapeseed oil is supposed to 


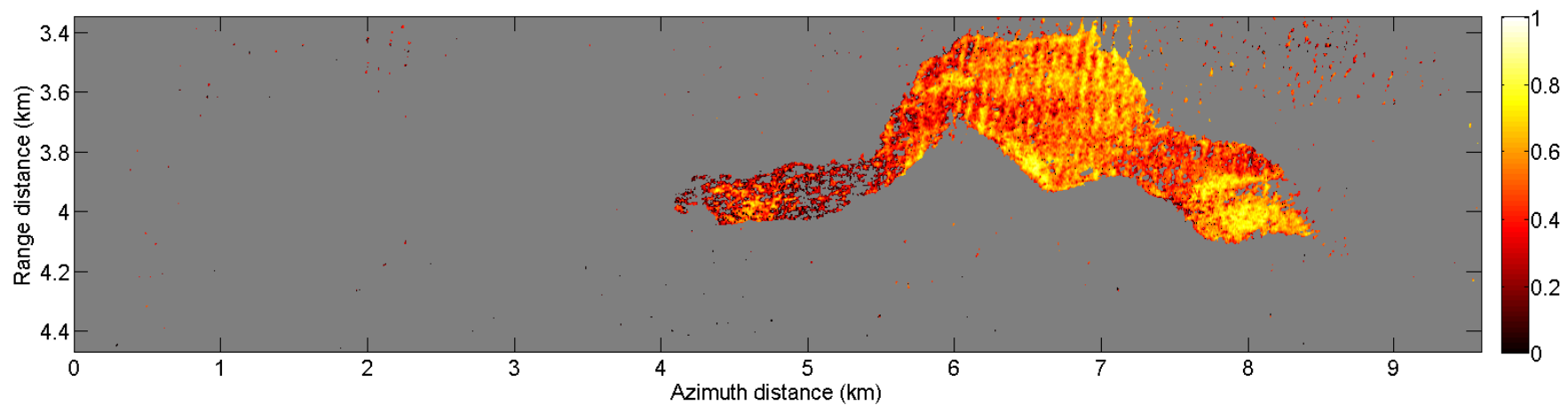

(a)

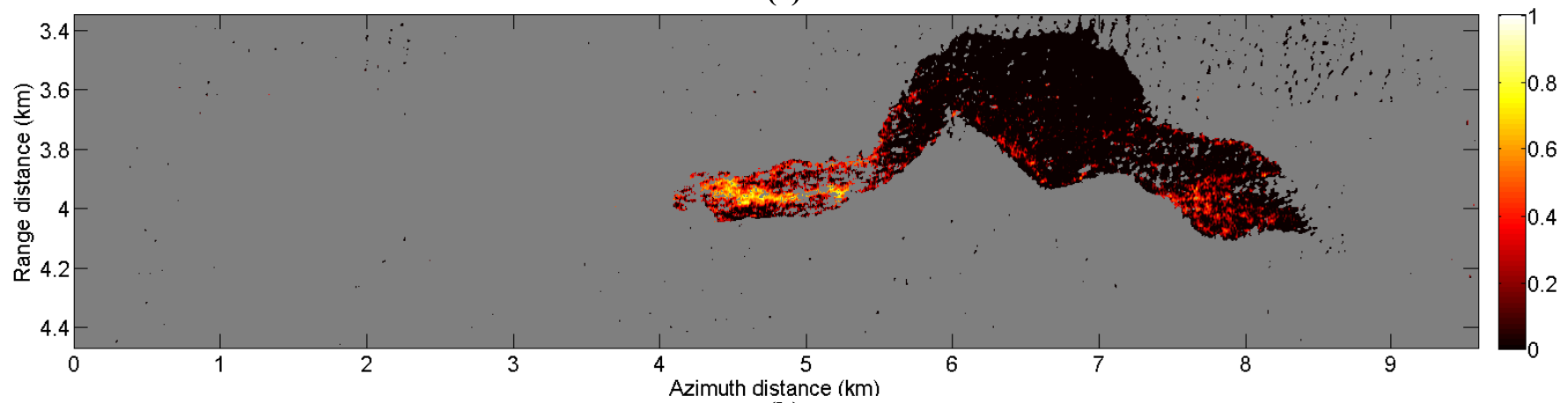

(b)

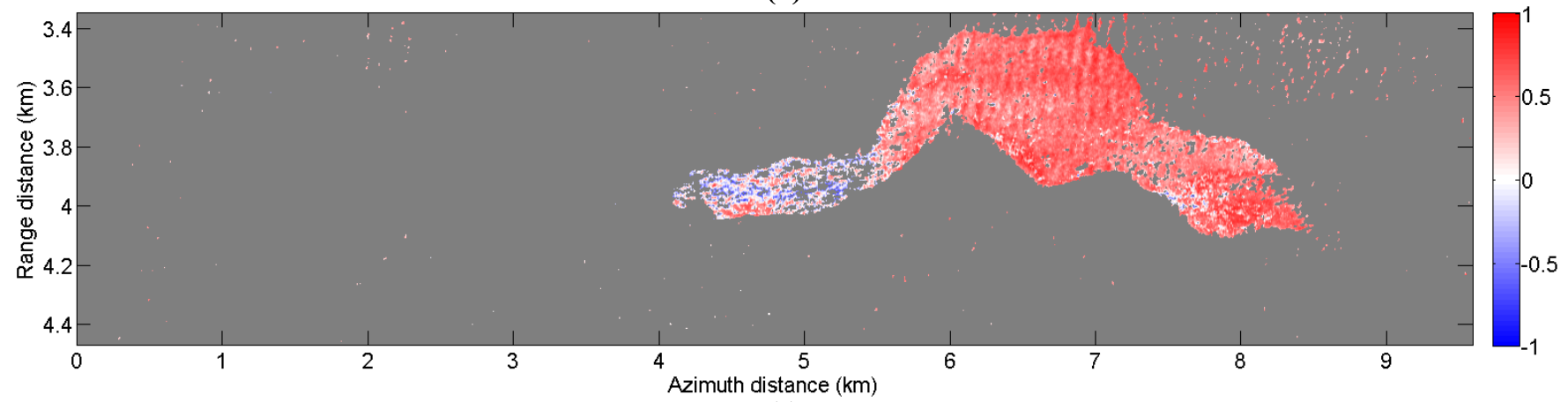

(c)

Fig. 10. (a) $M_{W}$, (b) $M_{\alpha}$, and (c) $M$ in the case of L-band acquisitions taken on May 22, 2015 at 16:07 UTC for FAME and rapeseed oil (multilook $7 \times 7$ ), crosswind observation.

remain above the surface and produce a film, while FAME will form a cloud in the water column composed of microdroplets. This is confirmed by observations made from the ship during the releases. These behaviors should be observable with SAR imagery as they impact the ocean surface in different ways.

Following the results presented in Section IV-B, we focus on L-band data and compute $M_{W}, M_{\alpha}$, and $M$ parameters using the method presented in Section III-C and initially published in [41]. As for NPD map (see Section IV-B), a detection map has been used beforehand and values have been computed for each pixel detected as contaminated using X-band data.

Fig. 10 shows the maps obtained over the releases for the normalized damping factor $\left(M_{W}\right)$, the normalized power attenuation factor $\left(M_{\alpha}\right)$, and the mixing index (M). First, gravity capillary waves are more damped on the right side of the spill than on the left side (lower $M_{W}$ values on average for the last than for the former). Inversely, the signal attenuation due to a decrease in the dielectric constant is higher on the left part than on the right part ( $\mathrm{M}_{\alpha}$ close to 0$)$. Finally, by combining these two pieces of information, we observe in the $M$ map the separation between the two chemicals constituting the spill [see Fig. 10(c)]. On average, $M$ is equal to 0.6 on the right part of the spill, which reveals the presence of a film on the sea surface, and $M$ is negative on the left part, meaning that the HNS is mixed with seawater with lower effect on the ocean surface roughness than on the right part. These behaviors match visual observations made during rapeseed oil and FAME discharges and are consistent with behaviors predicted by chemical and physical properties of each chemical (see Section II-B). L-band SAR data acquired at 16:20 UTC have also been investigated. The same results are generally obtained as for data acquired 13 min before, which confirms that the measured variation (between FAME and rapeseed oil) of $M_{\alpha}, M_{w}$, and $M$ parameters is related to the HNS and not caused by a temporal effect.

Maps of $M_{W}, M_{\alpha}$, and $M$ parameters obtained over the xylene release are shown in Fig. 11. The results presented in Figs. 10 and 11 show a similar behavior of xylene and rapeseed oil once released at sea. These two HNS form a 


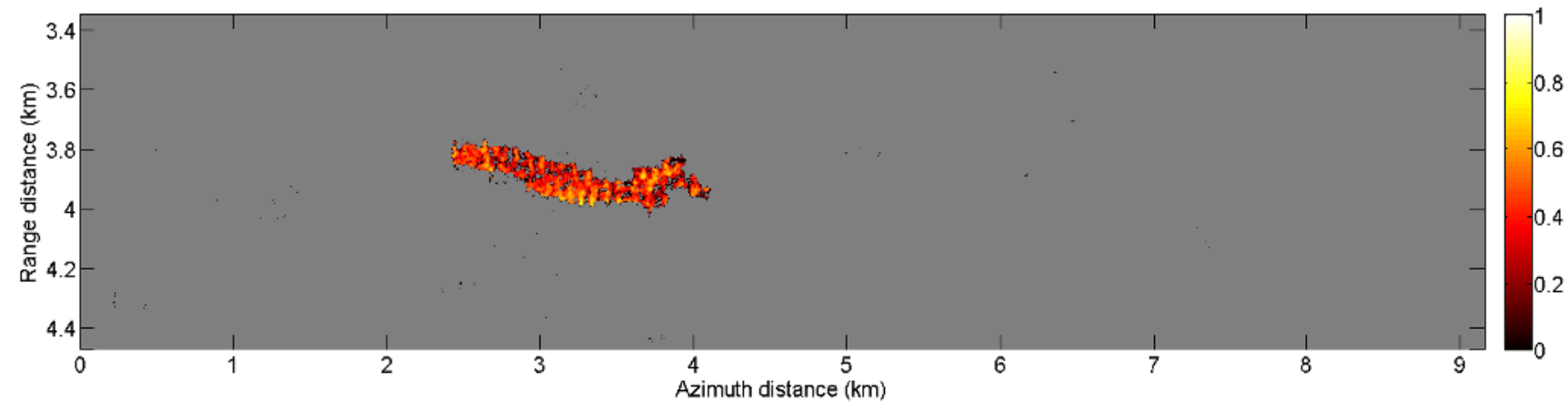

(a)

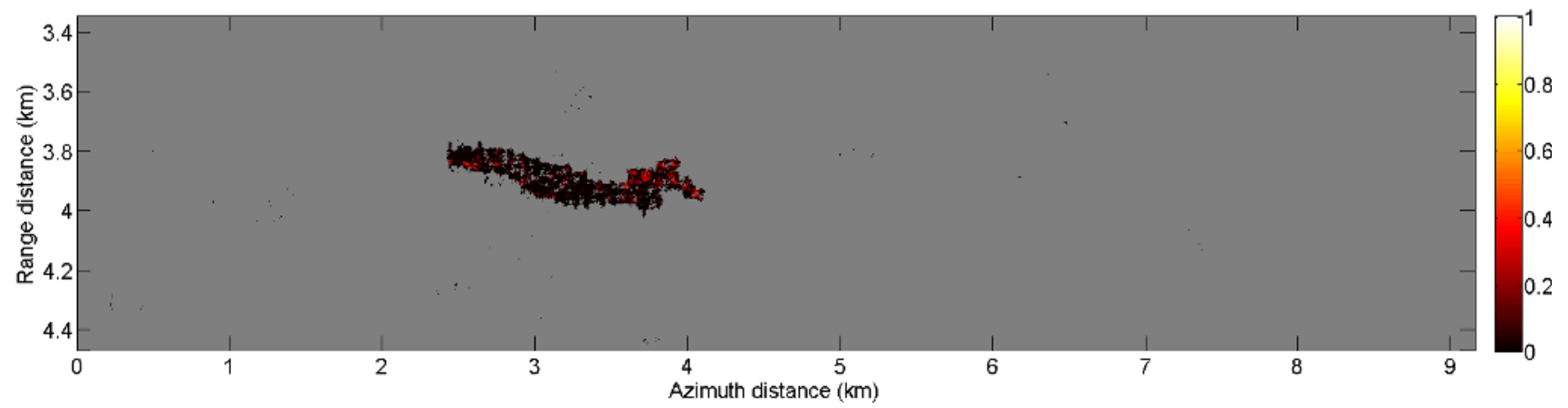

(b)

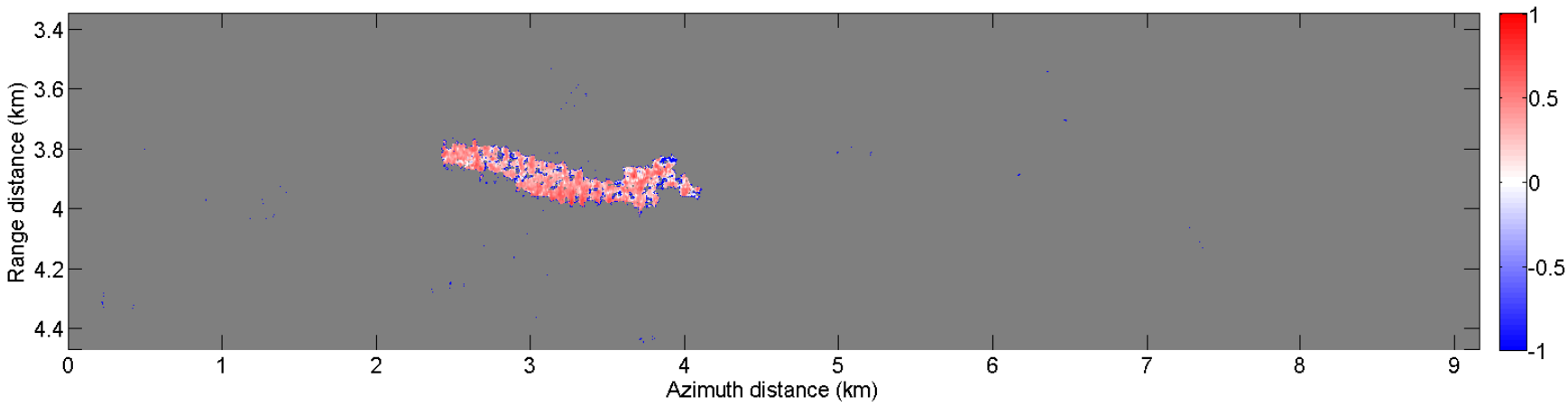

(c)

Fig. 11. (a) $M_{W}$, (b) $M_{\alpha}$, and (c) $M$ in the case of L-band acquisitions taken on May 22, 2015 at 13:29 UTC for xylene (multilook $7 \times 7$ ), crosswind observation.

film on the sea surface, while the FAME mixes in the water column.

Thus, analysis of NPD, $M_{W}, M_{\alpha}$, and $M$ parameters can be used to specify the behavior of the chemical product. Histograms of NPD, $M_{W}, M_{\alpha}$, and $M$ parameters computed with SAR data acquired at L-band over xylene (second flight), rapeseed oil, and FAME (third flight) are shown in Fig. 12. As discussed above, xylene and rapeseed oil have similar responses: $M_{\alpha}$ is close to 0 , which means that there is limited mixing with seawater, and $M_{W}$ and NPD at L-band are very similar and significantly high, indicating that signal attenuation is mainly due to the damping of the wind-driven sea surface waves and $M$ is equal to $0.4-0.6$, which corresponds to the presence of a film on the sea surface that damped the short waves. FAME has a different behavior: $M_{W}$ is lower than for the two other chemicals, $M_{\alpha}$ is no longer negligible, and thus $M$ takes positive and negative values, which means that, as expected, mixing is more present over FAME than over rapeseed oil and xylene. Note that these behaviors deduced from radar imagery analysis are not correlated with the SEBC classification. Indeed, FAME and rapeseed oil are classified as floater F in the SEBC, whereas in SAR, the FAME behavior is more like an FD with the presence of droplets into the water column, which is confirmed by visual observations made during the releases. Due to the variability of each parameter within the polluted area, the approach proposed in this paper could only be a region-based approach. Therefore, the use of $M_{W}, M_{\alpha}$, and $M$ parameters allows to distinguish an area contaminated by a substance that forms a film on the top of the sea surface from another area polluted by a product that mixes with seawater.

For the three chemicals, NPD at X-band is always significantly high (greater than 0.9). Over the FAME, NPD at L-band allows us to distinguish two areas (two peaks in the histogram located at 0.5 and 0.8 ) corresponding to two different concentrations, as it can be seen in Figs. 3 and 8. Interestingly, one can also observe a bimodal histogram for the $M_{\alpha}$ parameter, which confirms the presence of two different mixing. 

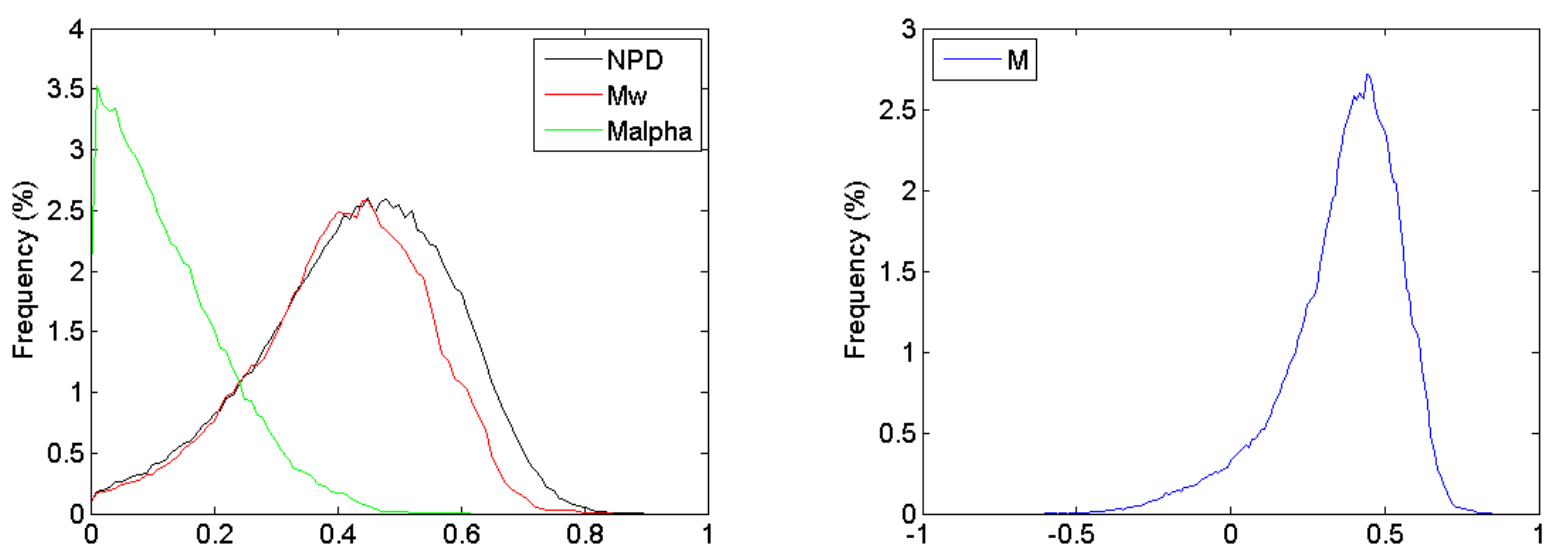

(a)
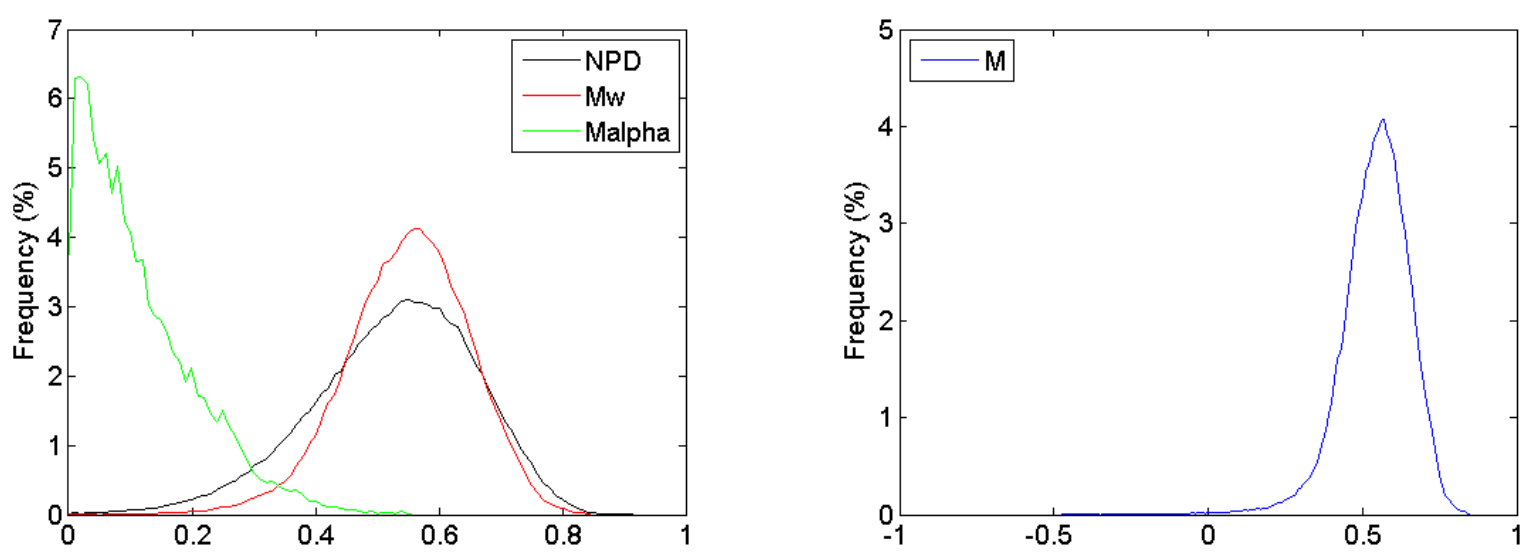

(b)
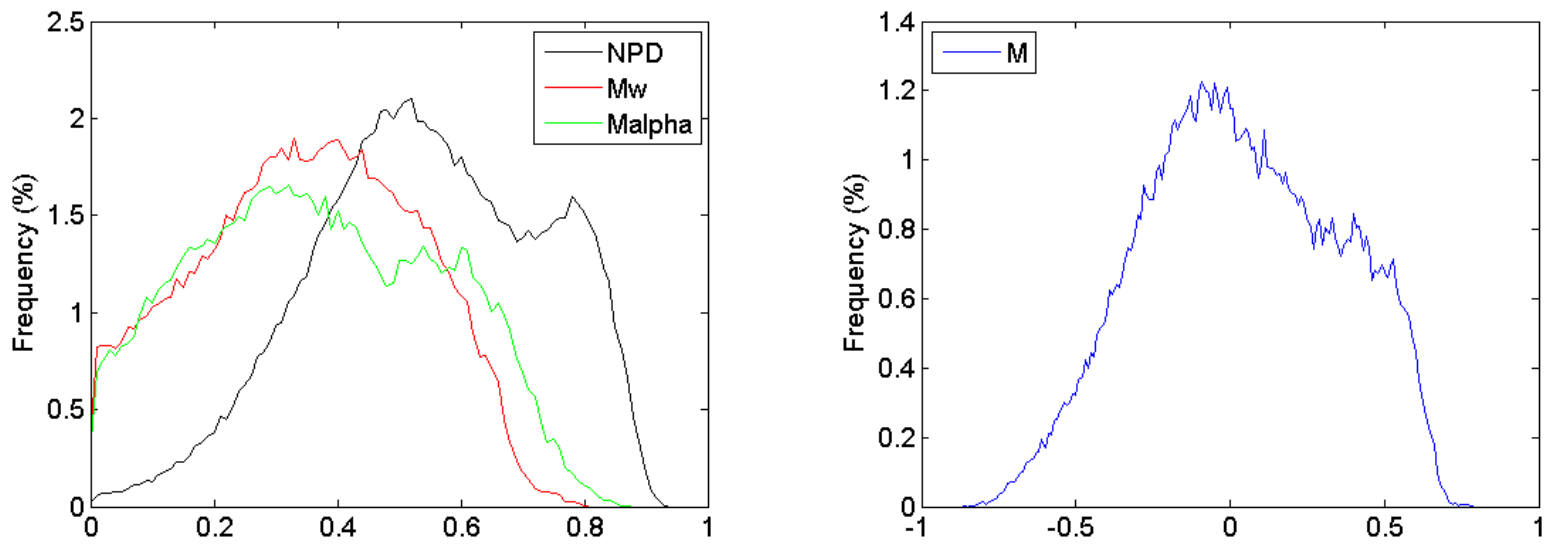

(c)

Fig. 12. Histograms over (a) xylene on 22 May 2015, 13:29 UTC, (b) rapeseed oil on 22 May 2015, 16:07 UTC, and (c) FAME on 22 May 2015, 16:07 UTC for L-band SAR data NPD (black curve), $M_{W}$ (red curve), $M_{\alpha}$ (green curve), and M (blue curve).

\section{CONCLUSion}

Motivated by the need for remote sensing technique to locate and characterize the HNS at sea, we developed the NPD, a metric for distinguishing contaminants from surrounding clean water, and demonstrated in a controlled experiment the utility of POLSAR data for quantifying chemical relative concentration and distinguishing between HNS that is manifest as a thin film and the HNS that mixes with seawater near the surface. The experiment, called POLLUPROOF, was conducted in May 2015 over the Mediterranean Sea and focused on the release and subsequent observation of several HNS products that are meant to represent the majority of commonly transported chemicals. The primary goal of this experiment is to establish a procedure for collecting evidence of illegal maritime pollution by HNS using airborne sensors. 
Of the six products tested during this experimentation at sea, we unambiguously detected three using SAR imagery. These detectable substances are rapeseed oil, FAME and xylene. For the three others, the nondetectability seems to be caused by a high volatility of tested products and a relatively long time lag between discharge and observations (especially for methanol release).

Using data collected over the detectable substances, we developed a methodology using $\mathrm{X}$ - and L-band radar imagery to detect and quantify the relative concentration of chemical products at sea. X-band is used to detect the slick and L-band is then used to quantify the relative concentration. A NPD parameter is then introduced for this purpose. NPD is a normalized parameter that, by design, provides only relative information about the impact of a liquid product released on the sea surface. We show that at L-band, the NPD parameter takes a wide range of values within the slick, a variation that is related to the impact of the released substance on the ocean surface. This impact depends on the concentration of chemical and can manifest itself in two different ways on the sea surface: smoothing of the sea surface due to the damping of the gravity capillary waves and a decrease in the dielectric constant compared with clean seawater due to a mix between HNS and pure seawater. Then we show that the distinction between two HNS within the same spill is possible with radar imagery by calculating the oil-water mixing index $(M)$. We conclude that, SAR data can allow us to define the characteristics of a spill along a spectrum ranging from thin surface films to natural dispersion (droplets in suspension in the water column). In summary, multifrequency POLSAR data can provide crucial information for efficient cleanup operations during HNS- or oil-related maritime pollution. The proposed methodology is as follows: NPD parameters, at X- and L-band, are recommended to detect and quantify the relative concentration of the involved substance and then the oil-water mixing parameters $\left(M_{W}, M_{\alpha}\right.$, and $M$ ) are recommended to characterize the behavior of the pollutant. Those pieces of information should be seen as a means of improving decision making by experts or operational staff. Automation of decisions is not guaranteed, as artifacts may appear, and a human intervention is usually necessary.

\section{APPENDIX}

The noise of the radar instrument, usually called NESZ, is a key parameter when studying maritime pollution as it appears on SAR images as dark patches, with low backscattered value and hence a potentially low SNR.

As discuss in Section II-A, SETHI instrument noise floor has been estimated using the method proposed in [28] and the results are shown in Fig. 13. At X-band, one can recognize the characteristic modulation induced by the antenna pattern with a minimum value corresponding to the maximum of illumination. At L-band, as half-power beamwidth is larger than that at $\mathrm{X}$-band $\left(33^{\circ}\right.$ and $16^{\circ}$ respectively) and as the imaged area is the same for the two frequency bands, the effect of the antenna pattern is less pronounced. The estimated NESZ is very low, ranging from around -37 to $-50 \mathrm{~dB}$ at $\mathrm{X}$-band and from around -51 to $-53 \mathrm{~dB}$ at L-band, allowing

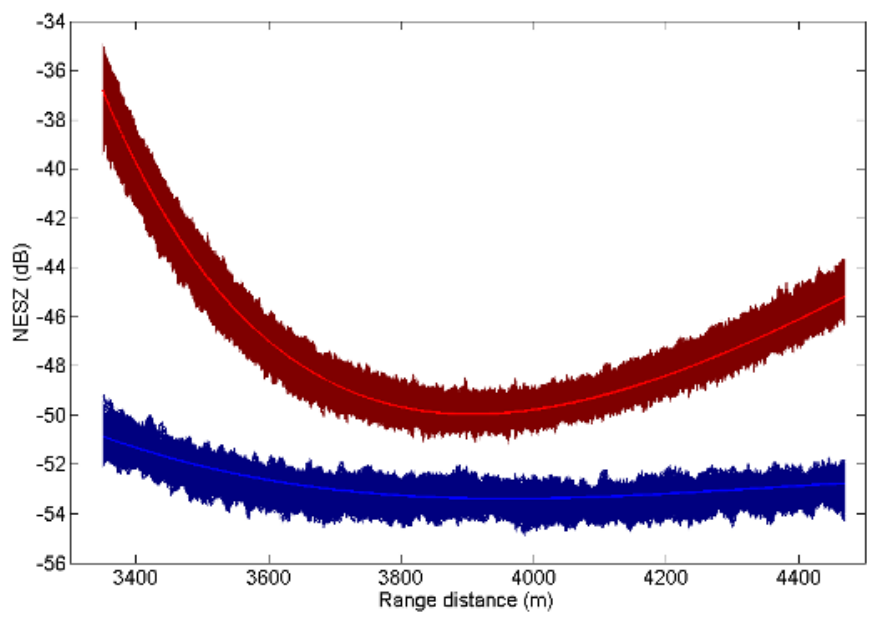

Fig. 13. SETHI instrumental noise floor at X-band (red curve) and L-band (blue curve).

a sufficient signal to noise ratio (see Fig. 4) over polluted areas for efficient analysis.

\section{ACKNOWLEDGMENT}

The authors would like to thank everyone involved in the experiment at sea (ONERA-CEDRE-AVDEF-DGDDIFrench Navy) and those who participated in the SAR data processing. They would also like to thank G. Soriano and C.-A. Guerin for the GO-SSA modeling and P.-D. Fernandez and $\mathrm{H}$. Oriot from ONERA for the successful discussions.

\section{REFERENCES}

[1] M. Fingas and C. Brown, "Review of oil spill remote sensing," Marine Pollution Bull., vol. 83, no. 1, pp. 9-23, 2014.

[2] C. Brekke and A. H. S. Solberg, "Oil spill detection by satellite remote sensing," Remote Sens. Environ., vol. 95, no. 1, pp. 1-13, 2005.

[3] M. Gade and W. Alpers, "Using ERS-2 SAR images for routine observation of marine pollution in European coastal waters," Sci. Total Environ., vols. 237-238, pp. 441-448, Sep. 1999.

[4] O. Garcia-Pineda, B. Zimmer, M. Howard, W. Pichel, X. Li, and I. R. MacDonald, "Using SAR images to delineate ocean oil slicks with a texture-classifying neural network algorithm (TCNNA)," Can. J. Remote Sens., vol. 35, no. 5, pp. 411-421, Oct. 2009.

[5] F. Girard-Ardhuin, G. Mercier, F. Collard, and R. Garello, "Operational oil-slick characterization by SAR imagery and synergistic data," IEEE J. Ocean. Eng., vol. 30, no. 3, pp. 487-495, Jul. 2005.

[6] A. Gambardella, G. Giacinto, M. Migliaccio, and A. Montali, "One-class classification for oil spill detection," Pattern Anal. Appl., vol. 13, no. 3, pp. 349-366, 2010.

[7] H. A. Espedal, O. M. Johannessen, J. A. Johannessen, E. Dano, D. R. Lyzenga, and J. C. Knulst, "COASTWATCH'95: ERS 1/2 SAR detection of natural film on the ocean surface," J. Geophys. Res., vol. 103, no. C11, pp. 24969-24982, 1998.

[8] G. R. Valenzuela, "Theories for the interaction of electromagnetic and oceanic waves-A review," Boundary-Layer Meteorol., vol. 13, nos. 1-4, pp. 61-85, Jan. 1978.

[9] V. Wismann, M. Gade, W. Alpers, and H. Huhnerfuss, "Radar signatures of marine mineral oil spills measured by an airborne multifrequency radar," Int. J. Remote Sens., vol. 19, no. 18, pp. 3607-3623, 1998.

[10] W. Alpers and H. Hühnerfuss, "The damping of ocean waves by surface films: A new look at an old problem," J. Geophys. Res., vol. 94, no. C5, pp. 6251-6265, 1989.

[11] A. H. S. Solberg, "Remote sensing of ocean oil-spill pollution," Proc. IEEE, vol. 100, no. 10, pp. 2931-2945, Oct. 2012.

[12] M. Migliaccio, A. Gambardella, and M. Tranfaglia, "SAR polarimetry to observe oil spills," IEEE Trans. Geosci. Remote Sens., vol. 45, no. 2, pp. 506-511, Feb. 2007.

[13] M. Migliaccio, A. Gambardella, F. Nunziata, M. Shimada, and O. Isoguchi, "The PALSAR polarimetric mode for sea oil slick observation," IEEE Trans. Geosci. Remote Sens., vol. 47, no. 12, pp. 4032-4041, Dec. 2009. 
[14] B. Zhang, W. Perrie, X. Li, and G. P. Pichel, "Mapping sea surface oil slicks using RADARSAT-2 quad-polarization SAR image," Geophys. Res. Lett., vol. 38, no. 10, pp. 1-5, 2011.

[15] S. Skrunes, C. Brekke, and T. Eltoft, "A comprehensive analysis of polarimetric features for oil spill characterization," in Proc. SeaSAR, vol. 2012. pp 203-210, 2012.

[16] R. Shirvany, M. Chabert, and J.-Y. Tourneret, "Ship and oil-spill detection using the degree of polarization in linear and hybrid/compact dual-pol SAR," IEEE J. Sel. Topics Appl. Earth Observ. Remote Sens., vol. 5, no. 3, pp. 885-892, Jun. 2012.

[17] F. Nunziata, A. Gambardella, and M. Migliaccio, "On the degree of polarization for SAR sea oil slick observation," ISPRS J. Photogramm. Remote Sens., vol. 78, pp. 41-49, Apr. 2013.

[18] B. T. Demin, S. A. Ermakov, E. N. Pelinovsky, T. G. Talipova, and A. I. Sheremeteva, "Study of the elastic properties of sea surface-active films," Izvestiva, Atmos. Ocean. Phys., vol. 21, no. 4, pp. 312-320, 1985.

[19] H. A. Espedal, "Satellite SAR oil spill detection using wind history information," Int. J. Remote Sens., vol. 20, no. 1, pp. 49-65, 1999.

[20] International Maritime Organization. accessed on Feb. 15, 2015 [Online]. Available: http://www.imo.org

[21] F. T. Ulaby, R. K. Moore, and A. K. Fung, Microwave Remote Sensing: Active and Passive. Dedham, MA, USA: Artech House, 1986.

[22] K. Purnell, "Are HNS spills more dangerous than oil spills?" in Proc. White Paper Interspill Conf. 4th IMO R\&D Forum, Marseille, France, May 2009. [Online]. Available: http://www.imo.org/en/OurWork/ Environment/PollutionResponse/Documents/White\%20paper\%20 Interspill\%202006\%20R\%20and\%20D\%20Forum.pdf

[23] International Tanker Owners Pollution Federation Limited, accessed on Feb. 15, 2015. [Online]. Available: http://www.itopf.com

[24] Database of Spill Incidents and Threats in Waters Around the World, accessed on Feb. 15, 2015. [Online]. Available: http://wwz.cedre.fr/en/ Our-resources/Spills

[25] Database of Hazardous and Noxious Substances Spill Incidents, accessed on Feb. 15, 2015. [Online]. Available: http://www.ciimar.up.pt/ hns/incidents.php

[26] S. Le Floch, "HNS detection and monitoring recent incidents and future considerations," in Proc. Interspill, 2009. [Online]. Available: http:// www.interspill.org/previous-events/2009/12-May/pdf/1530_floch.pdf

[27] G. Bonin et al., "The new ONERA multispectral airborne SAR system in 2009," in Proc. IEEE Radar Conf., Pasadena, CA, USA, May 2009, pp. 1-3.

[28] I. Hajnsek, E. Pottier, and S. R. Cloude, "Inversion of surface parameters from polarimetric SAR," IEEE Trans. Geosci. Remote Sens., vol. 41, no. 4, pp. 727-744, Apr. 2003.

[29] D. Mackay, W.-Y. Shiu, K.-C. Ma, and S. C. Lee, Handbook of PhysicalChemical Properties and Environmental Fate for Organic Chemicals, vol. 1. Boca Raton, FL, USA: CRC Press, 2006.

[30] D. Mackay, W.-Y. Shiu, K.-C. Ma, and S. C. Lee, Handbook of PhysicalChemical Properties and Environmental Fate for Organic Chemicals, vol. 3. Baco Raton, FL, USA: CRC Press, 2006.

[31] J. Harrison, N. D. C. Allen, and P. F. Bernath, "Infrared absorption cross sections for methanol," J. Quant. Spectrosc. Radiat. Transf., vol. 113 , no. 17, pp. 2189-2196, Nov. 2012.

[32] S. Skrunes, C. Brekke, and T. Eltoft, "Characterization of marine surface slicks by RADARSAT-2 multipolarization features," IEEE Trans. Geosci. Remote Sens., vol. 52, no. 9, pp. 5302-5319, Sep. 2014.

[33] B. Holt, "SAR imaging of the ocean surface," in Synthetic Aperture Radar (SAR) Marine User's Manual, C. R. Jackson and J. R. Apel, Eds. Silver Spring, MD, USA: NOAA, 2004, pp. 263-275.

[34] K. Hasselmann et al., "Theory of synthetic aperture radar ocean imaging: A MARSEN view," J. Geophys. Res., vol. 90, no. C3, pp. 4659-4686, 1985.

[35] B. Minchew, C. E. Jones, and B. Holt, "Polarimetric analysis of backscatter from the deepwater horizon oil spill using L-band synthetic aperture radar," IEEE Trans. Geosci. Remote Sens., vol. 50, no. 10, pp. 3812-3830, Oct. 2012.

[36] N. Pinel, C. Bourlier, and I. Sergievskaya, "Two-dimensional radar backscattering modeling of oil slicks at sea based on the model of local balance: Validation of two asymptotic techniques for thick films," IEEE Trans. Geosci. Remote Sens., vol. 52, no. 5, pp. 2326-2338, May 2014.

[37] S. Angelliaume, P. Dubois-Fernandez, V. Miegebielle, and D. Dubucq, "Polarimetric parameters for oil slicks detection using SAR data remote sensing-An evaluation," in Proc. IEEE Int. Geosci. Remote Sens. Symp. (IGARSS), Milan, Italy, Jul. 2015, pp. 3794-3797.

[38] V. N. Kudryavtsev, B. Chapron, A. G. Myasoedov, F. Collard, and J. A. Johannessen, "On dual co-polarized SAR measurements of the ocean surface," IEEE Geosci. Remote Sens. Lett., vol. 10, no. 4, pp. 761-765, Jul. 2013.
[39] C.-A. Guérin, G. Soriano, and B. Chapron, "The weighted curvature approximation in scattering from sea surfaces," Waves Random Complex Media, vol. 20, no. 3, pp. 364-384, 2010.

[40] A. Mouche and B. Chapron, "Global C-band ENVISAT, RADARSAT-2 and Sentinel-1 SAR measurements in copolarization and cross-polarization," J. Geophys. Res. Oceans, vol. 120, no. 11, pp. 7195-7207, 2015

[41] B. Minchew, "Determining the mixing of oil and sea water using polarimetric synthetic aperture radar," Geophys. Res. Lett., vol. 39, no. 16, p. L16607, 2012.

[42] G. Soriano and C.-A. Guérin, "A cutoff invariant two-scale model in electromagnetic scattering from sea surfaces," IEEE Geosci. Remote Sens. Lett., vol. 5, no. 2, pp. 199-203, Apr. 2008.

[43] M. Gade, W. Alpers, H. Hühnerfuss, H. Masuko, and T. Kobayashi, "Imaging of biogenic and anthropogenic ocean surface films by the multifrequency/multipolarization SIR-C/X-SAR," J. Geophys. Res., vol. 103, no. C9, pp. 18851-18866, 1998. 